\title{
Modeling Acceleration and Deceleration Rates for Two-Lane Rural Highways Using Global Positioning System Data
}

\author{
Vinayak Malaghan $\mathbb{D D}^{1,2}$ Digvijay S. Pawar $\mathbb{D}^{1},{ }^{1}$ and Hussein Dia $\mathbb{D}^{2}$ \\ ${ }^{1}$ Department of Civil Engineering, Indian Institute of Technology Hyderabad, Kandi, Medak 502285, India \\ ${ }^{2}$ Department of Civil and Construction Engineering, Swinburne University of Technology, Melbourne 3122, Australia
}

Correspondence should be addressed to Digvijay S. Pawar; dspawar@ce.iith.ac.in

Received 25 November 2020; Revised 14 April 2021; Accepted 17 April 2021; Published 26 April 2021

Academic Editor: Francesco Galante

Copyright (c) 2021 Vinayak Malaghan et al. This is an open access article distributed under the Creative Commons Attribution License, which permits unrestricted use, distribution, and reproduction in any medium, provided the original work is properly cited.

\begin{abstract}
Several past studies developed acceleration/deceleration rate models as a function of a single explanatory variable. Most of them were spot speed studies with speeds measured at specific locations on curves (usually midpoint of the curve) and tangents to determine acceleration and deceleration rates. Fewer studies adopted an estimated value of $0.85 \mathrm{~m} / \mathrm{s}^{2}$ for both deceleration and acceleration rates while approaching and departing curves, respectively. In this study, instrumented vehicles with a high-end GPS (global positioning system) device were used to collect the continuous speed profile data for two-lane rural highways. The speed profiles were used to locate the speeds at the beginning and end of deceleration/acceleration on the successive road geometric elements to calculate the deceleration/acceleration rate. The influence of different geometric design variables on the acceleration/ deceleration rate was analysed to develop regression models. This study also inspeced the assumption of constant operating speed on the horizontal curve. The study results indicated that mean operating speeds measured at the point of curvature (PC) or point of tangency (PT), the midpoint of curve (MC), and the end of deceleration in curve were statistically different. Acceleration/ deceleration rates as a function of different geometric variables improved the accuracy of models. This was evident from model validation and comparison with existing models in the literature. The results of this study highlight the significance of using continuous speed profile data to locate the beginning and end of deceleration/acceleration and considering different geometric variables to calibrate acceleration/deceleration rate models.
\end{abstract}

\section{Introduction}

Road infrastructure, vehicle, and human factors are the three concurrent factors causing road crashes $[1,2]$. Specifically, the road infrastructure factor accounts for 34 percent of road crashes [3]. As per the Ministry of Road Transport and Highways report, approximately 20,000 fatal crashes and 64,000 severe injuries were reported on curved roads in India [4]. One of the key factors responsible for these crashes is the lack of geometric design consistency relating drivers' expectations with the road geometric features. For this, the interaction between road infrastructure and human factors has been commonly studied for the evaluation of geometric design consistency. In this context, geometric design consistency can be defined as how likely the drivers' expectations are met with the geometric design features of the road
[5, 6]. A good consistent roadway optimizes surprising events and allows to maintain consistent operating speed meeting the drivers' expectations leading to safe maneuvers. Conversely, an inconsistent roadway brings in unexpected events for drivers, resulting in inconsistent operating speed and thereby increasing the chance of crashes [2].

There are various measures available to evaluate geometric design consistency: operating speed, side friction, vehicle dynamics, alignment indices, and mental workload $[7,8]$. Among these, operating speed measure is commonly used to develop speed profile models for the design consistency evaluation. There are two types of operating speed consistency models: local and global. Local consistency models are used to assess the design consistency of a single element (tangent or curve) or successive geometric elements (tangent and curve), whereas global consistency models are 
used to assess the consistency of the entire road segment [2]. Speed models along with the deceleration and acceleration rates when approaching and departing horizontal curves, respectively, are used in developing speed profiles for the design consistency evaluation of road segments [9].

Several studies assumed complete deceleration (or acceleration) on the tangents while approaching (or departing) a curve, and their rates equal to $0.85 \mathrm{~m} / \mathrm{s}^{2}$ [10-12]. Limited studies estimated deceleration/acceleration rate when approaching or departing horizontal curves for two-lane rural highways $[13,14]$. The studies mentioned above assumed constant speed on the horizontal curves and measured speed at the MC (midpoint of the curve) and specific locations on the tangents for the estimation of acceleration/ deceleration rate. Most of the studies measured the maximum operating speed at or below 200 or $300 \mathrm{~m}$ from PC on the total available tangent length [15-18]. A recent study by Malaghan et al. [19] found that deceleration begins even beyond 200 or $300 \mathrm{~m}$ on the long tangents, which needs to be considered while measuring maximum operating speed on the tangent, thereby in the calculation of acceleration/deceleration rate. Fewer studies developed acceleration/deceleration rate models using instrumented vehicle data $[5,20,21]$. Most of these studies developed deceleration and acceleration rate models depending on a single explanatory variable, i.e., horizontal curve radius [22]. The influence of different geometric design variables on the acceleration/ deceleration rates and an approach for selecting a final subset of variables from a set of geometric design variables for the proposed models were not detailed in the previously mentioned studies.

There is a direct correlation between operating speed variability or deceleration/acceleration rates on consecutive road geometric elements and crash rate to evaluate geometric design consistency [23, 24]. For instance, in the local consistency evaluation, the threshold values of speed reduction and deceleration/acceleration rate for the tangentto-curve (or curve-to-tangent) are considered for the design consistency checks as listed in Table 1 [24, 25]. The consistency index based on the inertial operating speed is another local design consistency evaluation method [9]. In this method, operating speed and deceleration/acceleration rate models are required to construct operating speed and inertial operating speed profiles. The difference in the speed profiles and crash rates are used to propose inertial consistency index (ICI) values to assess geometric design consistency.

The global consistency models predict the number of crashes on the road segment considering the entire road segment's overall speed variation [2]. The operating speed and inertial operating speed profiles are required to determine the consistency parameter in the global consistency model. Thus, operating speed, deceleration, and acceleration rate models are required to construct the speed profiles in both local and global consistency models.

The present study attempts to understand the deceleration and acceleration movements on the successive road geometric elements without making any assumptions about speed variation. The maximum operating speed (or beginning of deceleration) even beyond 200 or $300 \mathrm{~m}$ on the long tangents were measured to calculate the acceleration/ deceleration rate. The study also details the selection of the best explanatory variables from a set of variables to develop robust and reliable models for the prediction of acceleration and deceleration rates. In the present study, passenger cars equipped with a high-end global positioning system (GPS) were used to collect continuous speed profile data for twolane rural highways in India. All subset regression approach was used to inspect every possible model, and the best model is proposed to predict deceleration and acceleration rates.

This paper is organized as follows: Section 2 reviews the literature relevant to deceleration and acceleration rates while approaching and departing curves, respectively. Section 3 outlines the objectives of this research study. Section 4 presents the data and study methodology. The preliminary data analysis and model development are presented in subsequent Sections 5 and 6. The developed models are validated and compared with the existing models from the literature in Section 7. This is followed by a discussion in Section 8. The conclusions with the findings are listed in Section 9. Finally, the limitations and future research scope are presented in Section 10.

\section{Literature Review}

Previous research showed that limited studies are available to predict the deceleration and acceleration rates experienced by drivers while approaching and departing horizontal curves, respectively [22]. The literature relevant to the estimation of deceleration and acceleration rates can be divided into three groups based on the type of device used in data collection.

\subsection{Deceleration/Acceleration Rate Models Using Spot Speed} Measurements. Lamm et al. [10] marked eleven spots with 250 feet interval along the tangent section from the beginning of the curve to measure spot speeds. The authors studied the deceleration and acceleration movements from tangent-to-curve and curve-to-tangent at curves where speeds of $30 \mathrm{mph}, 35 \mathrm{mph}$, and $40 \mathrm{mph}$ were recommended. The deceleration (or acceleration) was found to begin (or end) at about 700 to 750 feet from the end of the curve. The study results also showed a difference of 4 to $5 \mathrm{mph}$ in operating speed between PC (point of curvature) and PT (point of tangency). The assumption of constant operating speed throughout the horizontal curves and entire deceleration (or acceleration) to complete on tangent sections was considered without statistical validation albeit speed difference was observed at the curve ends. Relating to a distance of 750 feet, the deceleration and acceleration rate of $0.85 \mathrm{~m} /$ $\mathrm{s}^{2}$ was proposed without validation. Further studies $[11,12,26]$ adopted this value of deceleration (or acceleration) rate to assess the geometric design consistency for two-lane rural highways. Collins and Krammes [13] tested the validity of proposed deceleration and acceleration rates $\left(0.85 \mathrm{~m} / \mathrm{s}^{2}\right)$. Operating speed was measured using infrared photoelectronic sensors at PC, PT, MC, and quarter-point of 
TABle 1: Design consistency evaluation checks.

\begin{tabular}{lccc}
\hline Evaluation & Speed reduction $(\mathrm{km} / \mathrm{h})$ & Deceleration rate $\left(\mathrm{m} / \mathrm{s}^{2}\right)$ & Acceleration rate $\left(\mathrm{m} / \mathrm{s}^{2}\right)$ \\
\hline Good & $\Delta V_{85}<10$ & 1.00 to 1.48 & 0.54 to 0.89 \\
Fair & $10<\Delta V_{85} \leq 20$ & 1.48 to 2.00 & 0.89 to 1.25 \\
Poor & $\Delta V_{85}>20$ & $>2.00$ & $>1.25$ \\
\hline
\end{tabular}

the curve (QP), and at every $60 \mathrm{~m}$ interval up to $240 \mathrm{~m}$ on the approach tangent from PC. The results of their study concluded that the value of $0.85 \mathrm{~m} / \mathrm{s}^{2}$ was reasonable for the deceleration rate while approaching the curve, whereas the value of $0.85 \mathrm{~m} / \mathrm{s}^{2}$ for the acceleration rate while departing horizontal curve was found statistically insignificant.

In the aforementioned studies, models to estimate the deceleration and acceleration rates were not developed. Also, the deceleration and acceleration rates estimated were based on the assumptions of entire speed variations on the approach/departure tangents and constant speed throughout the curve. Fitzpatrick et al. [27] measured free-flow speeds using Light Detection and Ranging (Lidar) guns at PC, PT, $\mathrm{MC}$, and QP, and at every $50 \mathrm{~m}$ interval up to $200 \mathrm{~m}$ on the tangent sections from the ends of a curve. The analysis results revealed that deceleration and acceleration occurred even inside the curves. The authors also found that the deceleration and acceleration rates were significantly different and not equal to $0.85 \mathrm{~m} / \mathrm{s}^{2}$. The authors developed a deceleration rate model as a function of radius for a specified range of radii and also presented the values of deceleration and acceleration rates for different ranges of radii as shown in Table 2.

A similar study by Figueroa and Tarko [28] measured speed using a speed gun at PC and PT, and at $91.4 \mathrm{~m}$ into approach and departure tangents from the ends of the curve to determine acceleration and deceleration rates. The authors developed acceleration and deceleration rate models by an iterative calibration process. The mean deceleration and acceleration rates were found to be approximately $0.732 \mathrm{~m} / \mathrm{s}^{2}$ and $0.488 \mathrm{~m} / \mathrm{s}^{2}$, respectively, for a $16.1 \mathrm{~km} / \mathrm{h}$ speed reduction. The results of their study concluded that made 66 percent of decelerations completed on approach tangents and 72 percent of acceleration on departure tangents from the ends of curves.

Previous studies measured operating speed at specific locations on the tangents and curves to determine acceleration/deceleration rate. Similarly, Sil et al. [29] determined that drivers rightly perceive and evaluate the curve sharpness $50 \mathrm{~m}$ ahead of the PC. Thus, drivers begin deceleration at $50 \mathrm{~m}$ from PC and end the deceleration at the MC to negotiate the curve. On the other hand, Jacob and Anjaneyulu [1] found that drivers begin their deceleration at $60 \mathrm{~m}$ from PC and attain minimum speed near the MC. The studies mentioned above developed operating speed models for geometric elements (tangents, curves, and tangent-to-curve) with speeds measured at specific locations. However, the studies did not determine the acceleration/deceleration rate.

In the abovementioned studies, spot speed devices allowed single point speed measurements at specified locations on the tangent and curve. To overcome this limitation and to understand speed variations precisely on the tangent-to-curve (or curve-to-tangent), continuous speed profiles were studied by several researchers using driving simulators and vehicles instrumented with GPS devices.

\subsection{Deceleration/Acceleration Rate Models Using Driving} Simulator. Bella [14] investigated the assumption of constant operating speed throughout the horizontal curve and also developed deceleration/acceleration rate models. The results of their statistical analysis supported the assumption of constant operating speed throughout the horizontal curve and the value of speed equal to that at the MC. The authors developed deceleration and acceleration rate models as a function of radius and maximum operating speed on a tangent. The acceleration/deceleration rates were calculated with speeds measured at the midpoint of the horizontal curves. The study concluded that the $85^{\text {th }}$ percentile value for deceleration and acceleration rates were not equal and significantly different from a value of $0.85 \mathrm{~m} / \mathrm{s}^{2}$. This conclusion is in line with the conclusion made by Fitzpatrick et al. [27]. Choudhari and Maji [30] did not support the assumption of constant operating on the horizontal curve. The authors measured operating speed at $200 \mathrm{~m}$ from PC on the tangent and speed on the curve at the end of deceleration to develop an $85^{\text {th }}$ percentile maximum speed reduction (85MSR) model.

On the other hand, a study by Montella et al. [16] used a driving simulator and analysed continuous speed profiles from tangent-to-curve and curve-to-tangent. The study findings did not support the assumption of constant operating speed on the horizontal curve, which is in line with the conclusion made by Bella [14]. The $85^{\text {th }}$ percentile deceleration rate for individual drivers was estimated to be $1.30 \mathrm{~m} / \mathrm{s}^{2}$. However, the $85^{\text {th }}$ percentile acceleration rate was found to be $0.85 \mathrm{~m} / \mathrm{s}^{2}$ for individual drivers, which is in agreement with the value recommended by Lamm et al. [10]. They also concluded that the acceleration/deceleration rates estimated from individual drivers were greater than those estimated considering the entire driver population.

Another study by Montella et al. [31] investigated continuous speed profiles obtained using a driving simulator and developed operating speed and acceleration/deceleration rate models for a two-lane rural highway. The deceleration rates were greater than the acceleration rates, which agree with other studies $[28,31,32]$. The deceleration rate was found to be 1.58 times higher than the acceleration rate for a curve with a radius of $800 \mathrm{~m}$. On a curve radius of $125 \mathrm{~m}$, the deceleration rate value was found to be 5 times higher than the acceleration rate. The value of deceleration and acceleration rates was found to be $0.77 \mathrm{~m} / \mathrm{s}^{2}$ and $0.29 \mathrm{~m} /$ $\mathrm{s}^{2}$, respectively, for middle curve radius $(R=400 \mathrm{~m})$. For curves with small radii, the end of deceleration was close to 
TABLE 2: Acceleration and deceleration rates.

\begin{tabular}{lccc}
\hline Radii range & Deceleration rate & Radii range & Acceleration rate \\
\hline$R \geq 436$ & $d=0.00$ & $R>875$ & $a=0.00$ \\
$175 \leq R<436$ & $d=0.6794-295.14 / R$ & $436 \leq R \leq 875$ & $a=0.21$ \\
& & $250<R \leq 436$ & $a=0.43$ \\
\hline$R<175$ & $d=1.00$ & $175<R \leq 250$ & $a=0.54$ \\
\hline
\end{tabular}

the midpoint of the curve (MC) and the beginning of deceleration near the curve end. With the increase in curve radii, the deceleration ended towards the point of curvature (PC), and acceleration began near the MC.

The limitations of driving simulators such as low-risk awareness, lack of dynamic visualization of road scenario, and limitations in vestibular and motion cues cannot make the driving task completely realistic [33]. Hence, vehicles instrumented with a GPS device were used to obtain data from the real-world to develop reliable acceleration and deceleration rate models.

\subsection{Deceleration/Acceleration Rate Models Using Vehicles} Instrumented with GPS. Pérez-Zuriaga et al. [20] equipped passenger cars with a GPS device to determine accurately the beginning and end of deceleration on the successive road geometric elements. The authors developed two deceleration rate models, one with a curvature change rate and the other with the radius as an explanatory variable. The results of their study indicated that 45 percent of the curve length is affected by deceleration and in 58 percent of sites, the deceleration ended before MC. Another study by PérezZuriaga et al. [21] proposed two deceleration rate models for tangent-to-curve transitions. The explanatory variable in the first model was radius whereas the shape of the transition curve was for the second model. The $85^{\text {th }}$ percentile values ranged between $0.3 \mathrm{~m} / \mathrm{s}^{2}$ and $1.7 \mathrm{~m} / \mathrm{s}^{2}$ for both asymptotic models. The results of their study also concluded that the hypothesis of the constant operating speed on the curves is only true in 8.35 percent of the cases.

Most of the past research performed data collection in the daytime and developed deceleration and acceleration rate models as a function of only one variable, i.e., horizontal curve radius [22]. Thus, $\mathrm{Hu}$ and Donnell [22] aimed to model acceleration and deceleration rates for complex twolane rural highways with experiments conducted during night-time. The explanatory variables for the models included several geometric variables such as horizontal curve length, curve radius, curve direction, and a vertical curve index. The acceleration and deceleration rates in their study ranged between $-1.34 \mathrm{~m} / \mathrm{s}^{2}$ and $+1.31 \mathrm{~m} / \mathrm{s}^{2}$. However, the applicability of the models for the road segments in daylight conditions was not validated.

Montella et al. [17] on the other hand studied driver behavior for speed choice and deceleration and acceleration performance on four-lane rural highways. The authors concluded that drivers' speed did not remain constant throughout the horizontal curves with 52 percent of drivers experiencing deceleration in the curves. The study also found that the values of acceleration and deceleration rates from individual drivers were greater than acceleration and deceleration rates used to draw speed profiles. Table 3 shows summary of deceleration and acceleration rate models from the existing literature.

A naturalistic driving study by Nama et al. [39] fitted a GPS device in passenger cars for the speed data collection on four-lane divided highways in mountainous terrain. The operating speed data were divided at every $4 \mathrm{~m}$ interval from tangent-to-curve and curve-to-tangent to draw an average position speed (APS) profile and acceleration/deceleration profile obtained from APS. The maximum, minimum, and average acceleration/deceleration rates were determined at every $4 \mathrm{~m}$ interval from the APS. The maximum deceleration and acceleration rate were determined to be 0.013 and $0.684 \mathrm{~m} / \mathrm{s}^{2}$, respectively. The geometric variables such as curve radius, tangent length, and gradient significantly influenced the acceleration/deceleration rate.

Most of the previous studies measured the operating speed at or below 200 or $300 \mathrm{~m}$ on the long tangents to develop speed and acceleration/deceleration rate models [15-18, 21, 30, 40-43]. A recent study by Malaghan et al. [19] analysed the distribution of maximum and minimum speed positions considering the entire length of tangent and curves. The results of the probability distributions showed that maximum speed positions (or beginning of deceleration) are found to occur even beyond 200 or $300 \mathrm{~m}$ on the long tangents. Authors found that the $85^{\text {th }}$ percentile maximum operating speed on the entire length of tangent $\left(V_{85 \operatorname{tmax}}\right)$ and the $85^{\text {th }}$ percentile speed measured at $200 \mathrm{~m}$ $\left(V_{85 \text { (app-max) }}\right)$ on the tangent are found to be significantly different. Hence, the speed at the beginning of deceleration (or maximum speed point) on the entire length of the long tangent should be considered to determine $V_{85 \operatorname{tmax}}$ and thereby calculate the $85^{\text {th }}$ percentile acceleration/deceleration rate. This results in accurate determination of speed, acceleration and deceleration rates, and classifying road geometric elements (e.g., good, fair, and poor) in evaluating design consistency.

The driver's heightened alertness due to GPS device presence in the short-term instrumented vehicle might influence the driver's normal operating speed (Dhahir and Yasser [44]). The drivers were informed about the purpose of fitting the GPS device to minimize its influence on driving behavior. The drivers were instructed that the GPS device will be fitted to the car's windshield, and the data collected will be utilized for the institute's research project and not for any legal enforcement. Also, the drivers were encouraged to drive as they usually do. In this way, drivers were encouraged to maintain normal driving behavior as they usually do. A similar approach was used by Montella et al. [17] and PérezZuriaga et al. [20] for collecting data using GPS devices. 
TABLE 3: Summary of the existing literature for acceleration and deceleration rate models.

\begin{tabular}{|c|c|c|c|c|c|}
\hline Authors & Country & RV & $\mathrm{EV}$ & Device & $\begin{array}{l}\text { No. of } \\
\text { lanes }\end{array}$ \\
\hline & & & Spot speed studies & & \\
\hline Marchionna and Perco [32] & Italy & $d, a$ & $R$ & \multirow{3}{*}{$\begin{array}{c}\text { Laser speed detection } \\
\text { NA } \\
\text { Light detection and ranging } \\
\text { (LIDAR) }\end{array}$} & Two-lane \\
\hline Fitzpatrick et al. [27] & US & $d, a$ & $R$ & & Two-lane \\
\hline Crisman et al. [34] & Italy & $d_{85}$ & $R$ & & Two-lane \\
\hline Bella [14] & Italy & $d_{85}, a_{85}$ & $\begin{array}{c}\text { Driving simulator } \\
\qquad R, V_{85 t} \\
\text { Instrumented vehicle }\end{array}$ & Driving simulator & Two-lane \\
\hline $\begin{array}{l}\text { Echaveguren and Basualto } \\
\text { [35] }\end{array}$ & Chile & $d_{85}$ & $R$ & GPS & Two-lane \\
\hline Montella et al. [17] & Italy & $d, a, d_{85}, a_{85}$ & $R, D_{a}, \mathrm{CCR}_{1}, \mathrm{CCR}_{2} G_{d}$, tunnel, $G_{u}$ & GPS & Four-lane \\
\hline Said et al. [36] & Canada & $d, a$ & $R$ & GPS & Two-lane \\
\hline Pérez-Zuriaga et al. [20] & Spain & $d_{85}$ & $R$ & GPS & Two-lane \\
\hline Pérez-Zuriaga et al. [21] & Spain & $d_{85}^{05}$ & $R$ & GPS & Two-lane \\
\hline Camacho-Torregrosa [5] & Spain & $d_{85}, a_{85}$ & $R$ & GPS & Two-lane \\
\hline Hashim et al. [37] & Egypt & $d_{85}$ & $R$ & GPS & Two-lane \\
\hline $\mathrm{Xu}$ et al. [38] & China & $d, a$ & $R, D_{a}$ & GPS & Two-lane \\
\hline
\end{tabular}

Note. RV: response variable; EV: explanatory variable; $d$ : deceleration rate; $a$ : acceleration rate; $d_{85}: 85^{\text {th }}$ percentile deceleration rate; $a_{85}: 85^{\text {th }}$ percentile acceleration rate; $R$ : radius; $V_{85 t}: 85^{\text {th }}$ percentile maximum speed on the tangent; $D_{\mathrm{a}}$ : deflection angle.

Summarizing the literature, the acceleration and deceleration rates were estimated approximately to an average value of $0.85 \mathrm{~m} / \mathrm{s}^{2}$. This value was proposed with speed measured at MC and specific locations on the approach/ departure tangents, assuming constant speed on the entire length of the curve. Further studies concluded that the acceleration and deceleration rates were not equal and different from the recommended value of $0.85 \mathrm{~m} / \mathrm{s}^{2}$. Hence, fewer studies developed models supporting the assumption mentioned above with speed measured at MC and predefined specific locations on the tangents. Other studies proposed models with speeds measured at the beginning and end of deceleration on the successive road geometric elements. However, most of the previous studies measured the maximum operating speed (or beginning of deceleration) at or below 200 or $300 \mathrm{~m}$ from PC of the total available tangent length on the long tangents. Besides, most of these models were developed with variation explained by one explanatory variable. The deceleration/acceleration rate models are not proposed for two-lane rural highways using continuous speed data in developing countries such as India. With this motivation, this study measured the operating speeds at the beginning and end of deceleration on the entire length of geometric elements (tangents and curve) to develop accurate acceleration/deceleration rate models.

\section{Objectives}

The specific objectives of this research study are to

(1) examine if any significant difference exists in operating speed measured at the midpoint of the curve (MC) and end of deceleration (minimum operating speed) on the horizontal curve;

(2) develop deceleration and acceleration rate models while approaching and departing horizontal curves as a function of various geometric design elements such as curve length $\left(L_{c}\right)$, curve radius $(R)$, deflection angle $\left(D_{a}\right)$, degree of curve $\left(D_{c}\right)$, preceding tangent length $\left(P_{\mathrm{t} 1}\right)$, and succeeding tangent length $\left(S_{\mathrm{t} 1}\right)$; and

(3) validate the proposed models with out-of-sample data and compare them with the deceleration and acceleration rate models from the literature to check the robustness of the proposed models in this study.

\section{Data and Study Methodology}

4.1. Geometric Data. Five two-lane rural highways in the states of Telangana and Karnataka, India, were selected to conduct the experiment. The alignment of the rural highways was determined as per the existing field conditions using Google Earth and highway design software (AutoCAD Civil 3D). The primary road geometric data such as curve radius, curve length, deflection angle, degree of curve, tangent length, and alignment length were obtained from the design software. Researchers studied the influence of curves with and without spiral transition on speed $[45,46]$. Their study's findings indicate that curves with spiral transitions did not significantly affect the speed at which passenger cars traversed the curves without spiral transitions. Hence, the spiral transition curves were not introduced between the horizontal curve and the tangent while determining the geometric design details of the existing road sections. Table 4 presents the summary of geometric features for the road segments. The secondary data such as lane width and paved and unpaved shoulder width were measured from the field. The carriageway width varied between 7.0 and $8.0 \mathrm{~m}$. The paved and earthen shoulder-width ranged from $1.0-1.5 \mathrm{~m}$ and $1.0-2.0 \mathrm{~m}$, respectively.

In this study, the selected road sections were visited, and pilot study concerning pavement condition was made during field visits. The pavement condition for the chosen 
TABLE 4: Summary of road segment characteristics.

\begin{tabular}{|c|c|c|c|c|c|c|c|}
\hline Roadway segment & Length $(\mathrm{km})$ & Statistic & $R(\mathrm{~m})$ & $L_{\mathrm{c}}(\mathrm{m})$ & $D_{\mathrm{a}}$ (degree) & $D_{\mathrm{c}}$ (degree) & TL $(\mathrm{m})$ \\
\hline \multirow{3}{*}{ NH 161} & \multirow{3}{*}{3.38} & Mean & 454.62 & 346.86 & 45.55 & 3.00 & 1570 \\
\hline & & SD & 185.72 & 181.84 & 17.45 & 1.27 & $1,031.88$ \\
\hline & & Range & $200-900$ & $90-785$ & $20-75$ & $1.35-5.75$ & $465-3,655$ \\
\hline \multirow{3}{*}{ SH 17} & \multirow{3}{*}{46.78} & Mean & 225 & 170.25 & 44.73 & 5.44 & 545 \\
\hline & & $\mathrm{SD}$ & 64.55 & 25.54 & 6.51 & 1.66 & 376.37 \\
\hline & & Range & $150-300$ & $135-200$ & $35-55$ & $3.80-7.65$ & $100-1,065$ \\
\hline \multirow{3}{*}{ SH 53} & \multirow{3}{*}{12.7} & Mean & 150 & 86.95 & 35.62 & 9.51 & 364.29 \\
\hline & & $\mathrm{SD}$ & 104.87 & 60.24 & 12.19 & 4.62 & 196.64 \\
\hline & & Range & $60-500$ & $45-310$ & $20-65$ & $2.45-19.10$ & $20-840$ \\
\hline \multirow{3}{*}{ SH 135} & \multirow{3}{*}{15.9} & Mean & 240.91 & 117.99 & 34.09 & 6.35 & 856.82 \\
\hline & & $\mathrm{SD}$ & 193.52 & 48.03 & 13.52 & 2.88 & 392.06 \\
\hline & & Range & $90-800$ & $60-225$ & $5-55$ & $1.40-12.75$ & $220-1,420$ \\
\hline \multirow{3}{*}{ MDR } & \multirow{3}{*}{3.2} & Mean & 100 & 68.87 & 46.53 & 14.56 & 405.63 \\
\hline & & $\mathrm{SD}$ & 67.33 & 27.56 & 21.45 & 6.30 & 290.46 \\
\hline & & Range & $60-200$ & $40-105$ & $20-75$ & $5.70-19.10$ & $120-1,040$ \\
\hline
\end{tabular}

Note. $R$ : radius, $L_{\mathrm{c}}$ : curve length, $D_{\mathrm{a}}$ : deflection angle, $D_{\mathrm{c}}$ : degree of curve, TL: tangent length, NH: national highway, SH: state highway, and MDR: major district road.

road sections was good without major pavement distresses affecting operating speed. The selected rural highway segments were away from the major intersections, and merging/ diverging approaches representing low traffic volume, and good pavement conditions to ensure the influence of road geometry on the operating speed.

4.2. GPS Data. The different types of light motor vehicles such as hatchback, sedan, and sports utility vehicles were used in data collection for two-lane rural highways. The different vehicle types were clubbed under one category, "passenger car" for further analysis and model development. The performance indicators of the passenger cars are presented in Table 5 . The passenger cars were fitted with a $10 \mathrm{~Hz}$ GPS data logger with the camera mounted on the front windshield below the rear-view mirror, magnetic antenna fixed on the rooftop, and GPS box placed near the dashboard, as shown in Figure 1. Vehicle speed, distance, time, position coordinates at every $0.1 \mathrm{~s}$, and high definition videos (1080p) at 60 frames per second (fps) were recorded and stored in the flash memory of the data logger. The experiment was conducted in the daytime under dry pavement conditions. Table 6 summarizes the number of samples collected for different road segments. The data collection was conducted by the research student with a total of 126 manhours spent in journey over a period of six months. The different classes of roads such as national highway, state highway, and major district road were included under category (NH/SH/MDR) for further analysis. The maximum speed achieved on the different road sections ranges between 85 and $115 \mathrm{~km} / \mathrm{h}$.

4.3. Participants' Profiles and Survey. A total of 49 individuals volunteered in this study. Participants had an average age of 33 years (standard deviation $=9.58$ years). The mean driving experience was 12 years (standard deviation $=9.77$ ). A face-to-face interview survey was conducted for each individual at the end of their respective trips.
The drivers' demographics data such as age, gender, driving experience, and occupation were collected. However, the demographics data were not included in the analysis for this study.

4.4. Data Extraction and Reduction. The speed variation along the distance was segmented depending on the lengths of approach tangent/departure tangents, and curve for each sample as shown in Figure 2. Section A-A to C-C shows segmented data for speed variation on the approach tangent, Section B-B to F-F for the horizontal curve, and Section F-F to $\mathrm{H}-\mathrm{H}$ for the departure tangent. The data were segmented referencing position coordinates using data analysis software (R studio) and highway design software. Speed variation on the approach tangent, horizontal curve, and departure tangent together constitutes a speed profile.

A minimum time headway between 4 and $6 \mathrm{~s}$ was recommended to avoid vehicular interaction to ensure the influence of road geometry on operating speed [8, 27, 47]. Hence, a time headway $\geq 5 \mathrm{~s}$ was considered for the speed profiles in the analysis. A total of 3,798-speed profiles were extracted while approaching and departing the curve. The speed profiles affected due to the influence of factors other than road geometry such as vehicle interaction (lead vehicles, overtaken vehicles, and oncoming traffic near or along the curve vicinity), sudden entry of animal (or pedestrian), speed hump on approach/departure tangents, and at PC/PT were removed. The removal of affected speed data resulted in 2,310-speed profiles for further analysis.

The segmented data on the approach/departure tangent and the horizontal curve were used to extract the maximum speed on the approach tangent at Section B-B, the speed at PC (Section C-C), the speed at MC (Section D-D), minimum speed at Section E-E, the speed at PT (Section F-F), and maximum speed on the departure tangent at Section G-G as shown in Figures 2(a) and 2(b). The speeds at the aforesaid locations were extracted for all the speed profiles considered in the analysis. 
TABle 5: Performance indicators for passenger car.

\begin{tabular}{lccccc}
\hline Type of vehicle & Max power (bhp) & Torque $(\mathrm{Nm})$ & Acceleration & Displacement capacity (cc) & Fuel economy (kml) \\
\hline Hatchback & $64.1-74$ & $113-190$ & $0-100 \mathrm{~km} / \mathrm{h} \mathrm{in} 12-18.7 \mathrm{~s}^{*}$ & $1172-1405$ & $16.7-26.55$ \\
Sedan & $67.04-70$ & $159.8-170$ & $0-100 \mathrm{~km} / \mathrm{h}$ in $10.6-17 \mathrm{~s} *$ & $1120-1364$ & 24 \\
Sports utility vehicles & $62.14-75$ & 195 & $0-100 \mathrm{~km} / \mathrm{h} \mathrm{in} 30 \mathrm{~s} * *$ & $2523-2596$ & $12-17$ \\
\hline
\end{tabular}

Note. $0-100 \mathrm{~km} / \mathrm{h}$ in $12-18.7 \mathrm{~s} .{ }^{*}=12$ to 18.7 seconds is required to reach the speed $100 \mathrm{~km} / \mathrm{h}$ from $0 ; 0-100 \mathrm{~km} / \mathrm{h}$ in $10.6-17 \mathrm{~s} .{ }^{* *}=10.6$ to 17 seconds is required to reach the speed $100 \mathrm{~km} / \mathrm{h}$ from 0 ; and $0-100 \mathrm{~km} / \mathrm{h}$ in $30 \mathrm{~s} .{ }^{* * *}=30 \mathrm{~s}$ is required to reach $100 \mathrm{~km} / \mathrm{h}$ from 0 .

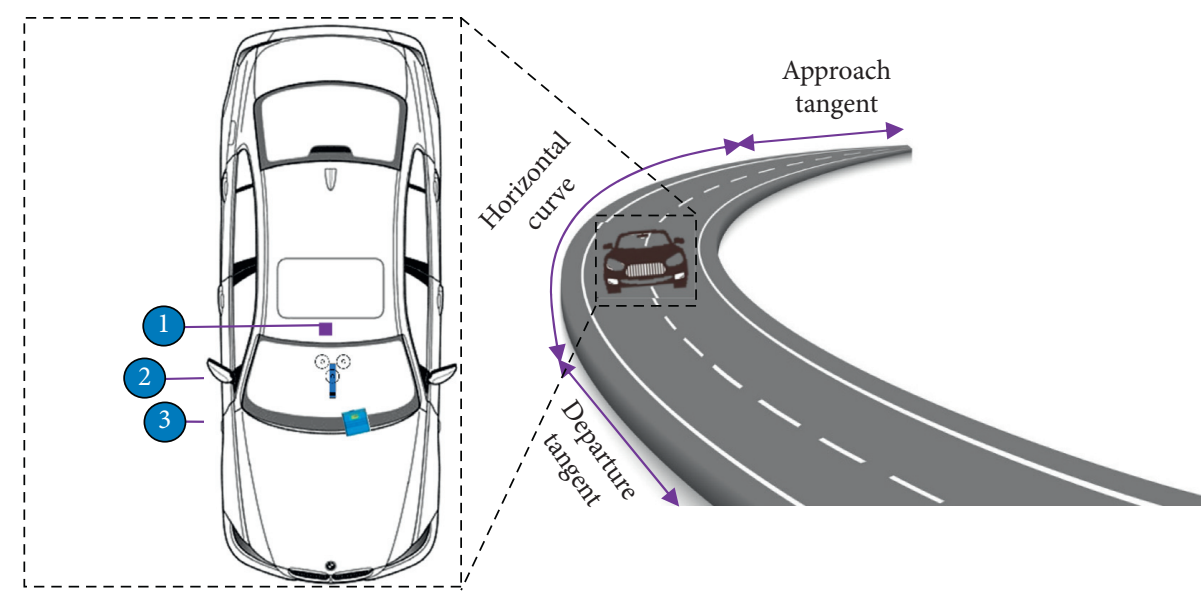
(1) Antenna
(2) Camera
(3) GPS box

FIGURE 1: Representation of geometric elements and vehicle instrumented GPS device.

TABLE 6: Summary of trips on geometric elements.

\begin{tabular}{lcccc}
\hline Roadway segment & No. of trips & No. of curves & No. of tangents & No. of independent tangents \\
\hline NH 161 & 48 & 4 & 5 & 4 \\
SH 135 & 91 & 11 & 15 & 15 \\
SH 53 & 87 & 17 & 24 & 17 \\
SH 17 & 70 & 13 & 20 & 20 \\
MDR & 54 & 4 & 6 & 5 \\
\hline
\end{tabular}

Note. A tangent is referred to as independent if its length is greater than $200 \mathrm{~m}$ [29].

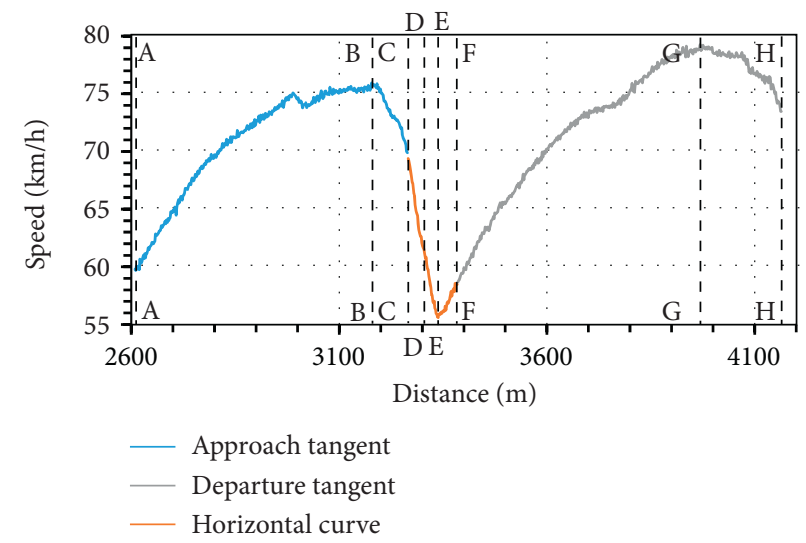

(a)

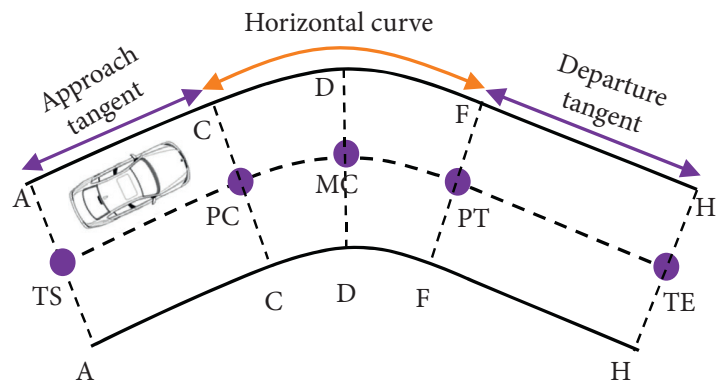

(b)

FIGURE 2: (a) Speed profile segmented for approach/departure tangent and horizontal curve and (b) representation of approach tangent, horizontal curve, and departure tangent. 
4.5. Regression and Statistical Tests. All subset regression approach was used for modeling acceleration and deceleration rates. This approach fits all the possible models based on the number of explanatory variables specified. For example, all subset regression approach fits $2^{n}$ models, where $n$ is the number of explanatory variables in the dataset [48]. The relative quality of the developed models is assessed using the Akaike information criterion (AIC) and $C_{p}$ Mallows' statistic.

4.5.1. Akaike Information Criteria. Akaike information criterion (AIC) is a mathematical method for an in-sample fit to predict the likelihood of a model to estimate future values [49]. In statistics, this criterion is used to test the relative quality of the different models for a given dataset. A best-fit model with the minimum AIC value explains the greatest variation with the fewest variables. The following equation is used to estimate the AIC values for the models:

$$
\mathrm{AIC}=-2 * \ln (L)+2 * k,
$$

where $L$ is the likelihood value and $k$ is the number of estimated parameters.

4.5.2. $C_{p}$ Mallows' Statistic. $C_{p}$ Mallows' statistic is another technique used for model choice in regression [50]. The $C_{p}$ statistic evaluates the models fit with different parameters when compared. The following equation is used to calculate $C_{p}$ statistic:

$$
C_{p}=\frac{\operatorname{RSS}_{(P)}}{\sigma^{2}}-N+2(p+1),
$$

where RSS is the residual sum of squares with $p+1$ variables, $\sigma^{2}$ is the residual mean square, $N$ is the sample size, and $p$ is the number regressors. A plot with $C_{p}$ statistic versus $p$ can be used to select a model.

\section{Preliminary Analysis}

5.1. Analysis for Speeds at Different Locations. Speed data extracted from randomly selected five horizontal curve sites were used to compare the speeds at locations such as PC/PT, $\mathrm{MC}$, and $C_{v \text { min }}$ (minimum speed location or the endpoint of deceleration) of a horizontal curve. A nonparametric test, Kolmogorov-Smirnov (K-S), was used to check the normality of speed data at a 5 percent level of significance. The normal probability distributions of speed data at different locations on the horizontal curve were plotted and presented in Figure 3. The parameters (mean and SD) of the normal distributions were estimated from the maximum likelihood method. The results of the K-S test and descriptive statistics of the speed data are presented in Table 7. The standard deviation (SD) of speed at PC/PT was $9.48 \mathrm{~km} / \mathrm{h}$, and approximately $6 \mathrm{~km} / \mathrm{h}$ at $\mathrm{MC} / C_{v \min }$. A higher standard deviation of speed at PC/PT is due to different lengths of short or long tangents approaching or departing a horizontal curve. The coefficient of variation (COV) measures relative variability in standard deviation from the mean. The higher value of $\mathrm{COV}$ at $\mathrm{PC} / \mathrm{PT}(\sim 0.14)$ indicates more variation in

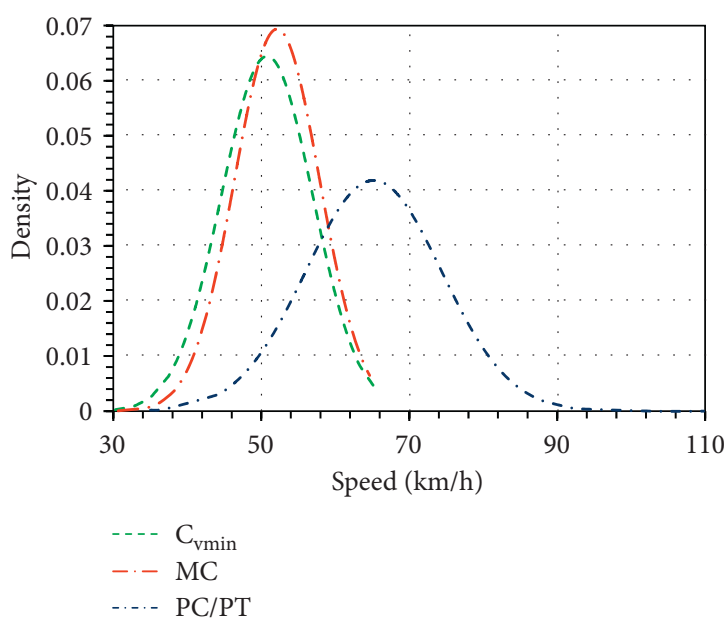

FIGURE 3: Normal probability distribution plots for speed.

the speed at $\mathrm{PC} / \mathrm{PT}$ in comparison to that at the $\mathrm{MC} / C_{v \min }$ ( 0.11). The speed distributions at $\mathrm{MC}$ and $C_{v \min }$ were negatively skewed whereas positively skewed at PC/PT. The measure of central tendency (mean) confirmed the greater speed choice at PC/PT compared to $\mathrm{MC}$ and $C_{v \min }$ (see Figure 3 and Table 7). The results for curve sites showed the ascending order of mean speed values at different locations on horizontal curves: $\mathrm{PC} / \mathrm{PT}>\mathrm{MC}>C_{v \min }$.

An analysis of variance (ANOVA) test was performed to examine whether a statistically significant difference in mean speeds existed between speeds measured at different locations (PC/PT, MC, and $C_{v \min }$ ) on the horizontal curves [51]. The formulation of the hypotheses was as follows:

$H_{0}$ : the mean of speeds at different locations on the horizontal curve is statistically the same

$H_{1}$ : the mean of speeds at different locations on the horizontal curve is statistically different

There was a statistically significant difference between group means of operating speeds measured at different locations as determined by one-way ANOVA $F(2,1085)=506.72, p<0.001$. Tukey's honestly significant difference (Tukey's HSD) test was conducted to determine the pairwise difference in mean speeds at different locations [52]. The pairwise differences between group means of operating speeds at a 5 percent significance level are presented in Table 8 . The mean operating speeds at PC/PT and $C_{v \text { min }}$ were significantly different from one another $(p<0.05)$. Similarly, mean operating speeds at MC and PC/ PT were significantly different from each other. A pairwise difference in mean speeds between $\mathrm{MC}$ and $C_{v \min }$ was not significantly different. The confidence interval with 0 specifies pairs that are not significantly different.

The results of this study indicated that mean speeds at $C_{v \min }$ and MC were not statistically different. However, the acceleration/deceleration rate was calculated without making any assumption for the occurrence of minimum speed at a specific location, i.e., MC, for more accurate results. The following equation is used to compute the $85^{\text {th }}$ percentile acceleration/deceleration rate: 
TABLe 7: Descriptive statistics and K-S test results.

\begin{tabular}{lcccccrrr}
\hline \multirow{2}{*}{ Locations } & \multicolumn{2}{c}{ Parameters } & \multirow{2}{*}{ Maximum $(\mathrm{km} / \mathrm{h})$} & \multirow{2}{*}{ Minimum $(\mathrm{km} / \mathrm{h})$} & \multirow{2}{*}{ COV } & Skewness & \multirow{2}{*}{ K-S value } & $p$ value \\
& Mean & SD & & & & & \\
\hline PC/PT & 66.71 & 9.48 & 112.28 & 64.63 & 30.00 & 0.14 & 0.54 & 0.03 \\
MC & 52.12 & 5.75 & 65.77 & 30.26 & 0.11 & -0.43 & 0.05 \\
$C_{v \min }$ & 50.77 & 6.19 & & 0.12 & -0.39 & 0.05 & 0.45 \\
\hline
\end{tabular}

TABLE 8: Tukey's HSD test results.

\begin{tabular}{lccc}
\hline \multirow{4}{*}{ Groups } & \multicolumn{2}{c}{$95 \%$ confidence } & \\
& \multicolumn{2}{c}{ interval } & $p$ value \\
& Lower & Upper & \\
\hline PC/PT- $C_{v \text { min }}$ & 14.57 & 17.33 & $<0.001$ \\
MC- $C_{v \min }$ & -0.24 & 2.95 & 0.12 \\
MC-PC/PT & -5.98 & -3.21 & $<0.001$ \\
\hline
\end{tabular}

$$
d_{85}=\frac{\left(V_{85 t}-V_{85 c}\right)}{2 S},
$$

where $V_{85 t}$ is the $85^{\text {th }}$ percentile maximum speed on the tangent, $V_{85 c}$ is the $85^{\text {th }}$ percentile minimum speed on the curve, and $S$ is the distance between them.

5.2. Correlation Test. A bivariate Pearson correlation analysis was performed to assess the strength of association between variables. The correlation coefficients are translated to descriptors based on the cutoff points: very weak $(0.00-0.10)$, weak $(0.10-0.39)$, moderate $(0.40-0.69)$, strong $(0.70-0.89)$, and very strong $(0.90-1.00)$ [53]. The linear correlation between variables $x$ and $y\left(r_{x y}\right)$ for a given set of observations $(n)$ is considered statistically significant if $\left|r_{x y}\right| \geq 2 / \sqrt{n}$ as per the rule of thumb [54]. The threshold values $(2 / \sqrt{n})$ between variables for acceleration and deceleration rates are presented in Table 9.

The correlation matrix with correlation coefficient values between the variables is displayed in the upper triangle as shown in Figure 4. The correlation between curve length $\left(L_{c}\right)$, curve radius $(R)$, deflection angle $\left(D_{a}\right)$, degree of curve $\left(D_{c}\right)$, preceding tangent length $\left(P_{\mathrm{t}}\right)$, succeeding tangent length $\left(S_{\mathrm{tl}}\right)$, and $85^{\mathrm{th}}$ percentile deceleration rate $\left(d_{85}\right)$ is shown in Figure 4(a). Similarly, the correlation between various geometric design variables and the $85^{\text {th }}$ percentile acceleration rate is shown in Figure 4(b). Positive correlations are shown in blue whereas negative correlations are shown in red color. In the diagram, color intensity is proportional to the value of the correlation coefficient. The statistical significance for correlation between variables is checked at a 95 percent significance level, and an insignificant relation is displayed without any color. The color intensity pattern is observed to be similar for both the correlation plots (see Figures 4(a) and 4(b)). The correlation between variables is rational and in the expected direction. Curve length and curve radius showed a strong negative correlation with the deceleration/acceleration rate whereas the degree of curve showed a strong positive correlation with the deceleration/acceleration rate. A moderate correlation was observed between the preceding tangent length and the
TABle 9: Thresholds for the bivariate correlation.

\begin{tabular}{llcc}
\hline Sr. No. & Parameter & $n$ & $2 / \sqrt{n}$ \\
\hline 1 & Deceleration rate & 49 & 0.29 \\
2 & Acceleration rate & 43 & 0.31 \\
\hline
\end{tabular}

deceleration/acceleration rate. Geometric design variables (curve length, curve radius, degree of curve, deflection angle, and tangent lengths) showed a moderate to a strong correlation between them.

\section{Model Formulation}

A regression model in the form given by equation (4) was formulated to estimate deceleration and acceleration rates while approaching or departing horizontal curves:

$$
y_{i} \sim \gamma_{0}+\gamma_{1} x_{1}+\gamma_{2} x_{2}+\cdots+\gamma_{n} x_{n}
$$

The response variable $y_{i}$ can be $85^{\text {th }}$ percentile deceleration rate $\left(d_{85}\right)$ or $85^{\text {th }}$ percentile acceleration rate $\left(a_{85}\right)$. The explanatory variables $\left(x_{1}, x_{2}, \ldots, x_{n}\right)$ can be either of the geometric design variables such as curve length $\left(L_{c}\right)$, curve radius $(R)$, deflection angle $\left(D_{a}\right)$, degree of curve $\left(D_{c}\right)$, preceding tangent length $\left(P_{\mathrm{t}}\right)$, and succeeding tangent length $\left(S_{\mathrm{t} 1}\right)$. The following conditions of the regression models were satisfied:

(a) The coefficients of the explanatory variables were statistically significant at a 95 percent confidence interval

(b) The relation between the response and explanatory variables was in the expected direction with rational interpretation

(c) The value of variation inflation factor (VIF) was below a certain threshold value such that multicollinearity was not found among independent variables

(d) The models satisfied the assumptions made in the OLS (ordinary least square) regression

6.1. Deceleration Rate Model. The deceleration rate for each tangent-to-curve transition of all the road segments was calculated from equation (3). The process was repeated to all the collected sample data. Then, the $85^{\text {th }}$ percentile deceleration rate $\left(d_{85}\right)$ was determined for each tangent-to-curve transition. Regression models were developed with the $85^{\text {th }}$ percentile deceleration rate as a function of various geometric design variables. In this study, six simple linear and eight multiple linear regression models were developed. The 


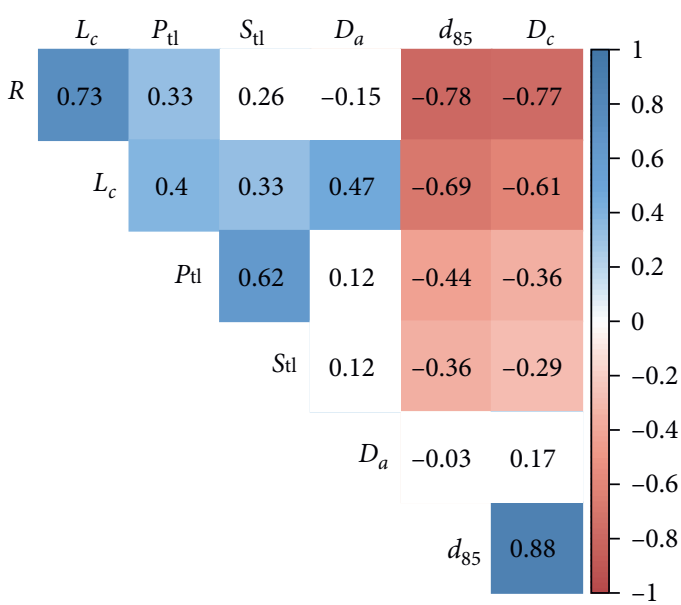

(a)

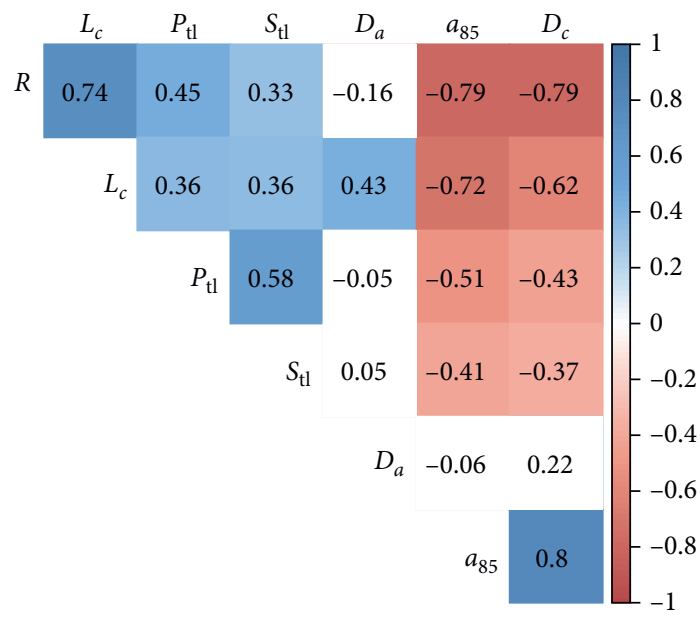

(b)

FIgURE 4: Bivariate correlation matrix: (a) deceleration rate and (b) acceleration rate.

summary of the analysis results for fourteen regression models is tabulated in Table 10.

The results of the correlation analysis showed a moderate to a strong correlation among independent variables. The developed models were checked for multicollinearity between independent variables. The variation inflation factor (VIF) is a measure to determine the degree of multicollinearity [48]. As per the rule of thumb, $\sqrt{\mathrm{VIF}}>2$ indicates the presence of multicollinearity affecting the performance of a model [48]. The values of VIF for all the developed models were found to be lower than the values that can be estimated from the rule of thumb. Thus, the performance of the developed models was not affected due to multicollinearity.

Adjusted $R$-square, Mallows $C_{p}$ statistic, and Akaike information criteria (AIC) were used to propose the best model from the various developed models. Figure 5(a) shows the adjusted $R$-square values corresponding to independent variables. Each row in Figure 5(a) represents a set of independent variables that were included in a model. The results of every possible model or $n$ best models of each subset size (one-predictor, two-predictors up to allpredictors) can be displayed. In this plot (as shown in Figure 5(a)), $n$ best $=1$ was chosen to display the adjusted $R$ square value for one best one-predictor model, followed by one best two-predictor model, followed by one best threepredictors up to a model including all-predictors. The coefficients of the variables in each of the models above the sixth row were statistically insignificant at a 95 percent confidence interval. Hence, model 14 with intercept, curve radius, degree of curve, and deflection angle (sixth row from bottom) having a higher adjusted $R$-square value of 0.82 was chosen (as shown in Table 10).

Mallows $C_{p}$ statistic and AIC are two important and commonly used metrics for model selection. Figure 5(b) is a $C_{p}$ plot for all subset regression with $C_{p}$ statistic on the $y$-axis and subset size on the $x$-axis. In this plot $n$ best $=1$ was considered to display one best model of each subset size. The models close to the line are considered as the best models. Looking at Figure 5(b), models with subset sizes 3, 4, 5, and 6 are close to the line. However, the coefficients of independent variables in models with subset sizes 4,5 , and 6 were statistically insignificant at a 95 percent confidence interval. Hence, a model with three-predictors (curve radius, degree of curve, and deflection angle) close to the line was selected. The AIC values for all the fourteen developed models were computed and presented in Table 10. From all the three measures (adjusted $R$-square, $C_{p}$ statistic, and AIC), model 14 with curve radius, degree of curve, and deflection angle as explanatory variables was considered as the best estimator of the $85^{\text {th }}$ percentile deceleration rate.

The goodness-of-fit $\left(R^{2}\right)$ measure of the proposed model is 0.83 indicating that 83 percent variation in the deceleration rate is explained by curve radius, degree of curve, and deflection angle. The $p$ values for the $t$-tests indicated that the slope parameters for curve radius ( $p$ value $=0.009$ ), degree of curve $(p$ value $<0.001)$, and deflection angle $(p$ value $=0.004)$ were significantly different from zero at a 95 percent significance level. The Global Stat (second row in Table 11) corresponding to the deceleration rate indicated that the data satisfied all the statistical assumptions (linearity, homoscedasticity, uncorrelatedness, and normality) that go with the ordinary least square regression model $(p=0.60)$. Table 11 also presents separate evaluations for kurtosis, heteroscedasticity, link function, and skewness.

A negative sign of regression coefficients for curve radius and deflection angle indicated an inverse relation with the deceleration rate. The relation is consistent with an $85^{\text {th }}$ percentile deceleration rate model presented by Montella et al. [17]. The curves become smoother and flatter for higher values of radii and deflection angles, allowing lower speed reduction, and thereby decrease in deceleration rates. A positive sign of the coefficient for the degree of curve indicates direct relation with the deceleration rate. With the increase in the degree of curve, the driver feels that the curve becomes sharper resulting in higher deceleration rate. 
TABLE 10: Summary of analysis results for $85^{\text {th }}$ percentile deceleration rate models.

\begin{tabular}{|c|c|c|c|c|c|c|c|c|}
\hline Model No. & Model & EV & VIF & SE & $t$-stat & $p$ value & $R^{2}$ & AIC \\
\hline 1 & $d_{85}=2.580-0.375 \ln (R)$ & $R$ & - & 0.029 & -13.03 & $<0.001$ & 0.783 & -52.142 \\
\hline 2 & $d_{85}=2.245-0.342 \ln \left(L_{c}\right)$ & $L_{c}$ & - & 0.033 & -10.38 & $<0.001$ & 0.696 & -35.580 \\
\hline 3 & $d_{85}=-0.058+0.374 \ln \left(D_{c}\right)$ & $D_{c}$ & - & 0.029 & 13.028 & $<0.001$ & 0.783 & -52.115 \\
\hline 4 & $d_{85}=0.895-0.001 R$ & $R$ & - & 0.000 & -8.567 & $<0.001$ & 0.610 & -23.308 \\
\hline 5 & $d_{85}=0.816-0.001 L_{c}$ & $L_{c}$ & - & 0.000 & -6.605 & $<0.001$ & 0.481 & -9.395 \\
\hline 6 & $d_{85}=0.195+0.056 D_{c}$ & $D_{c}$ & - & 0.004 & 12.67 & $<0.001$ & 0.774 & -50.001 \\
\hline \multirow{2}{*}{7} & \multirow{2}{*}{$d_{85}=0.907-0.001 R-0.001 L_{c}$} & $R$ & 2.157 & 0.000 & -4.537 & $<0.001$ & 0.642 & -25.513 \\
\hline & & $L_{c}$ & 2.157 & 0.000 & -2.030 & 0.048 & & \\
\hline \multirow{2}{*}{8} & \multirow{2}{*}{$d_{85}=0.382-3.867 \times 10^{-04} R+0.044 D_{c}$} & $R$ & 2.484 & 0.000 & -2.407 & 0.020 & 0.799 & -53.815 \\
\hline & & $D_{c}$ & 2.484 & 0.007 & 6.581 & $<0.001$ & & \\
\hline \multirow{2}{*}{9} & \multirow{2}{*}{$d_{85}=0.935-0.001 R-8.981 \times 10^{-05} P_{\mathrm{tl}}$} & $R$ & 1.119 & 0.000 & -7.706 & $<0.001$ & 0.648 & -26.352 \\
\hline & & $P_{\mathrm{tl}}$ & 1.119 & 0.000 & -2.233 & 0.030 & & \\
\hline \multirow{2}{*}{10} & \multirow{2}{*}{$d_{85}=0.349-5.059 \times 10^{-04} L_{c}+0.046 D_{c}$} & $L_{c}$ & 1.589 & 0.000 & -3.133 & 0.003 & 0.813 & -57.481 \\
\hline & & $D_{c}$ & 1.589 & 0.005 & 9.047 & $<0.001$ & & \\
\hline \multirow{2}{*}{11} & \multirow{2}{*}{$d_{85}=0.583-0.002 L_{c}+0.008 D_{a}$} & $L_{c}$ & 1.279 & 0.000 & -8.149 & $<0.001$ & 0.591 & -19.048 \\
\hline & & $D_{a}$ & 1.279 & 0.002 & 3.514 & 0.001 & & \\
\hline \multirow{2}{*}{12} & \multirow{2}{*}{$d_{85}=0.327+0.058 D_{c}-0.004 D_{a}$} & $D_{c}$ & 1.030 & 0.004 & 13.868 & $<0.001$ & 0.807 & -55.869 \\
\hline & & $D_{a}$ & 1.030 & 0.001 & -2.830 & 0.007 & & \\
\hline \multirow{2}{*}{13} & \multirow{2}{*}{$d_{85}=0.265+0.053 D_{c}-6.287 \times 10^{-05} P_{\mathrm{tl}}$} & $D_{c}$ & 1.145 & 0.005 & 11.504 & $<0.001$ & 0.792 & -52.129 \\
\hline & & $P_{\mathrm{tl}}$ & 1.145 & 0.000 & -2.011 & 0.050 & & \\
\hline \multirow{3}{*}{14} & \multirow{3}{*}{$d_{85}=0.522-3.985 \times 10^{-04} R+0.046 D_{c}-0.004 D_{a}$} & $R$ & 2.485 & 0.000 & -2.700 & 0.009 & 0.834 & -61.225 \\
\hline & & $D_{c}$ & 2.504 & 0.006 & 7.411 & $<0.001$ & & \\
\hline & & $D_{a}$ & 1.031 & 0.001 & -3.087 & 0.004 & & \\
\hline
\end{tabular}

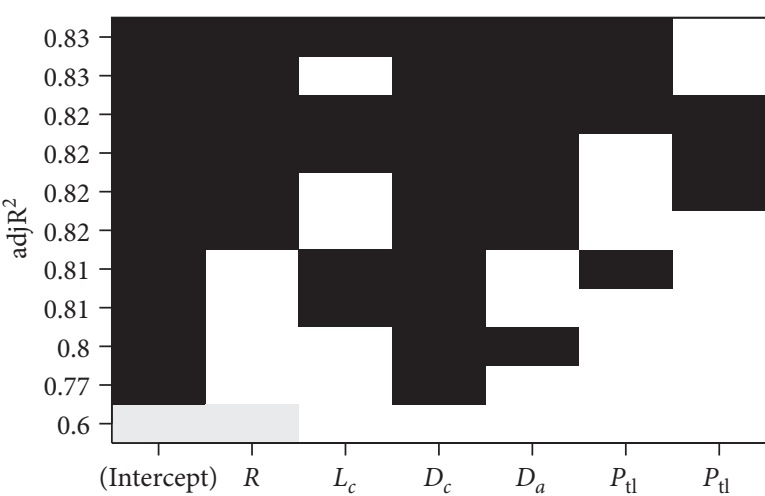

(a)

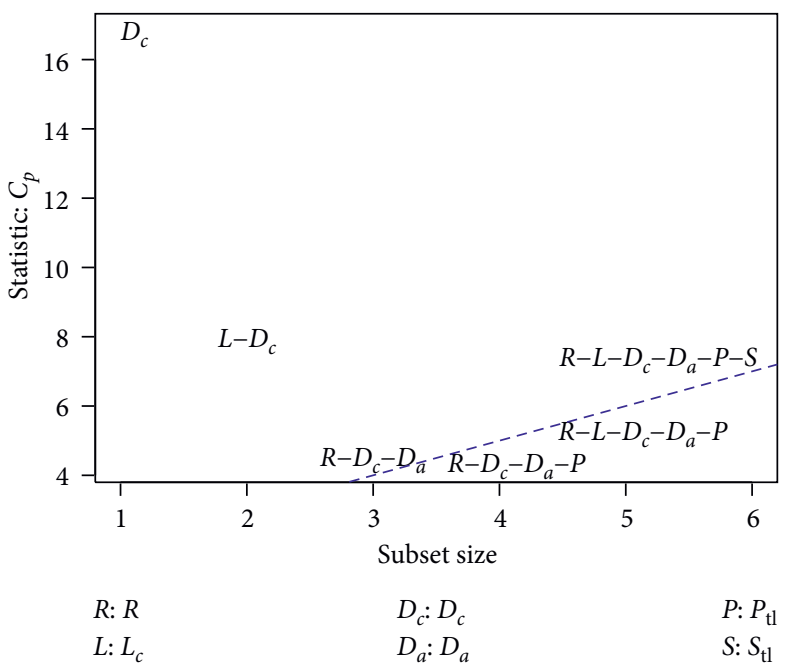

(b)

Figure 5: Model selection based on (a) adjusted $R$-square and (b) $C_{p}$ statistic.

6.2. Acceleration Rate Model. Acceleration rates for each curve-to-tangent transition of all sample data were calculated using equation (3). Then, the $85^{\text {th }}$ percentile acceleration rates $\left(a_{85}\right)$ were determined for each curve-to-tangent transition. All subset regression approach was used to develop six simple linear and ten multiple linear regression models. Table 12 presents a summary of the analysis results for all models. The results of VIF indicated that independent variables in the models were not associated with multicollinearity. The regression coefficients for the variables in rows 3, 5, and 6 (starting from the bottom) are statistically insignificant at a 95 percent confidence interval (see Figure 6(a)). Hence, a model in row 4 with coefficients of variables significant at a 95 percent confidence interval having an adjusted $R$-square value of 0.75 was chosen.

In Figure 6(b), the line passes through the models with three-predictors, five-predictors, and six-predictors. However, the regression coefficients in models with fivepredictors and six-predictors were statistically insignificant at a 95 percent confidence interval. Based on the highest adjusted $R$-square, $C_{p}$ statistic, and lowest AIC values, a model 14 with curve radius, degree of curve, and deflection 
TABLE 11: Global validation of linear model assumptions.

\begin{tabular}{|c|c|c|c|c|c|}
\hline \multirow{2}{*}{ Measures } & \multicolumn{2}{|c|}{ Deceleration rate } & \multicolumn{2}{|c|}{ Acceleration rate } & \multirow{2}{*}{ Decision } \\
\hline & Value & $p$ value & Value & $p$ value & \\
\hline Global Stat & 2.745 & 0.601 & 1.569 & 0.814 & Assumption acceptable \\
\hline Skewness & 1.381 & 0.240 & 0.199 & 0.655 & Assumption acceptable \\
\hline Kurtosis & 0.005 & 0.946 & 0.0006 & 0.980 & Assumption acceptable \\
\hline Link function & 0.317 & 0.574 & 0.853 & 0.356 & Assumption acceptable \\
\hline Heteroscedasticity & 1.043 & 0.307 & 0.516 & 0.473 & Assumption acceptable \\
\hline
\end{tabular}

TABLE 12: Summary statistics of $85^{\text {th }}$ percentile acceleration rate models.

\begin{tabular}{|c|c|c|c|c|c|c|c|c|}
\hline Model No. & Model & $\mathrm{EV}$ & VIF & SE & $t$-stat & $p$ value & $R^{2}$ & AIC \\
\hline 1 & $a_{85}=1.395-0.188 \ln (R)$ & $R$ & - & 0.018 & -10.350 & $<0.001$ & 0.723 & -85.327 \\
\hline 2 & $a_{85}=1.273-0.180 \ln \left(L_{c}\right)$ & $L_{c}$ & - & 0.019 & -9.580 & $<0.001$ & 0.691 & -80.600 \\
\hline 3 & $a_{85}=0.076-0.188 \ln \left(D_{c}\right)$ & $D_{c}$ & - & 0.018 & 10.361 & $<0.001$ & 0.724 & -85.368 \\
\hline 4 & $a_{85}=0.569-6.480 \times 10^{-04} R$ & $R$ & - & 0.000 & -8.386 & $<0.001$ & 0.632 & -73.026 \\
\hline 5 & $a_{85}=0.528-7.577 \times 10^{-04} L_{c}$ & $L_{c}$ & - & 0.000 & -6.623 & $<0.001$ & 0.517 & -61.356 \\
\hline 6 & $a_{85}=0.211+0.026 D_{c}$ & $D_{c}$ & - & 0.003 & 8.460 & $<0.001$ & 0.636 & -73.501 \\
\hline \multirow{2}{*}{7} & \multirow{2}{*}{$a_{85}=0.387-3.584 \times 10^{-04} R+0.015 D_{c}$} & $R$ & 2.626 & 0.000 & -3.183 & 0.003 & 0.709 & -81.206 \\
\hline & & $D_{c}$ & 2.626 & 0.005 & 3.269 & 0.002 & & \\
\hline \multirow{2}{*}{8} & \multirow{2}{*}{$a_{85}=0.654-6.727 \times 10^{-04} R+0.002 D_{a}$} & $R$ & 1.026 & 0.000 & -8.941 & $<0.001$ & 0.668 & -75.457 \\
\hline & & $D_{a}$ & 1.026 & 0.000 & -2.084 & 0.043 & & \\
\hline \multirow{2}{*}{9} & \multirow{2}{*}{$a_{85}=0.331-3.864 \times 10^{-04} L_{c}+0.019 D_{c}$} & $L_{c}$ & 1.614 & 0.000 & -3.445 & 0.001 & 0.719 & -82.670 \\
\hline & & $D_{c}$ & 1.614 & 0.004 & 5.366 & $<0.001$ & & \\
\hline \multirow{2}{*}{10} & \multirow{2}{*}{$a_{85}=0.428-8.958 \times 10^{-04} L_{c}+0.003 D_{a}$} & $L_{c}$ & 1.228 & 0.000 & -7.597 & $<0.001$ & 0.592 & -66.642 \\
\hline & & $D_{a}$ & 1.228 & 0.001 & 2.718 & 0.010 & & \\
\hline \multirow{2}{*}{11} & \multirow{2}{*}{$a_{85}=0.565-6.488 \times 10^{-04} L_{c}-6.503 \times 10^{-05} P_{\mathrm{tl}}$} & $L_{c}$ & 1.151 & 0.000 & -5.653 & $<0.001$ & 0.588 & -66.171 \\
\hline & & $P_{\mathrm{tl}}$ & 1.151 & 0.000 & -2.621 & 0.012 & & \\
\hline \multirow{2}{*}{12} & \multirow{2}{*}{$a_{85}=0.301+0.028 D_{c}-0.003 D_{a}$} & $D_{c}$ & 1.053 & 0.002 & 9.564 & $<0.001$ & 0.697 & -79.406 \\
\hline & & $D_{a}$ & 1.053 & 0.000 & -2.841 & 0.007 & & \\
\hline \multirow{2}{*}{13} & \multirow{2}{*}{$a_{85}=0.271+0.023 D_{c}-4.572 \times 10^{-05} P_{\mathrm{tl}}$} & $D_{c}$ & 1.231 & 0.003 & 7.035 & $<0.001$ & 0.669 & -75.550 \\
\hline & & $P_{\mathrm{tl}}$ & 1.231 & 0.000 & -1.987 & 0.050 & & \\
\hline \multirow{3}{*}{14} & \multirow{3}{*}{$a_{85}=0.470-3.485 \times 10^{-04} R+0.017 D_{c}-0.002 D_{a}$} & $R$ & 2.628 & 0.000 & -3.407 & 0.002 & 0.767 & -88.611 \\
\hline & & $D_{c}$ & 2.699 & 0.004 & 4.059 & $<0.001$ & & \\
\hline & & $D_{a}$ & 1.054 & 0.001 & -3.088 & 0.004 & & \\
\hline \multirow{3}{*}{15} & \multirow{3}{*}{$a_{85}=0.477-7.831 \times 10^{-04} L_{c}+2.560 \times 10^{-03} D_{a}-5.156 \times 10^{-05} P_{\mathrm{tl}}$} & $L_{c}$ & 1.502 & 0.000 & -6.259 & $<0.001$ & 0.634 & -69.288 \\
\hline & & $D_{a}$ & 1.309 & 0.001 & 2.220 & 0.032 & & \\
\hline & & $P_{\mathrm{tl}}$ & 1.226 & 0.000 & -2.109 & 0.041 & & \\
\hline \multirow{3}{*}{16} & \multirow{3}{*}{$a_{85}=0.354-0.003 D_{c}+2.550 \times 10^{-03} D_{a}-4.269 \times 10^{-05} P_{\mathrm{tl}}$} & $D_{c}$ & 1.295 & 0.000 & 8.075 & $<0.001$ & 0.725 & -81.647 \\
\hline & & $D_{a}$ & 1.056 & 0.000 & -2.843 & 0.007 & & \\
\hline & & $P_{\mathrm{tl}}$ & 1.234 & 0.000 & -2.011 & 0.050 & & \\
\hline
\end{tabular}

angle as explanatory variables was proposed. The coefficient of determination $\left(R^{2}\right)$ of the proposed model is 0.77 . This tells us that 77 percent variation in acceleration rate is explained by curve radius, degree of curve, and deflection angle. The proposed model for the acceleration rate satisfied the assumptions made in the OLS regression $(p=0.814=)$ as presented in Table 11.

The curve radius and deflection angle showed a negative correlation with the acceleration rate whereas the degree of curve resulted in a positive correlation with the acceleration rate. The curve becomes smoother and flatter for greater values of curve radii and deflection angles, leading to lower speed changes on the successive road geometric elements (in this case from curve to tangent) and thereby lower acceleration rates while departing the curve. The driver perceives curve getting sharper for the higher values of degree of curve, leading to lower speeds on horizontal curves. This is accompanied by higher acceleration rates to achieve higher speeds while departing curves.

\section{Model Validation and Comparison}

The out-of-sample data were collected at road segments with similar geometric features considered in the model development. The proposed models for acceleration and deceleration rates were validated using out-of-sample data. Also, proposed models from this study and existing models in the literature were compared to determine their degree of correspondence to the out-of-sample data. Several studies developed deceleration/acceleration rate models for twolane and four-lane rural roads located in different types of terrain $[16,17,20-22,27,38,39]$. The explanatory variables 

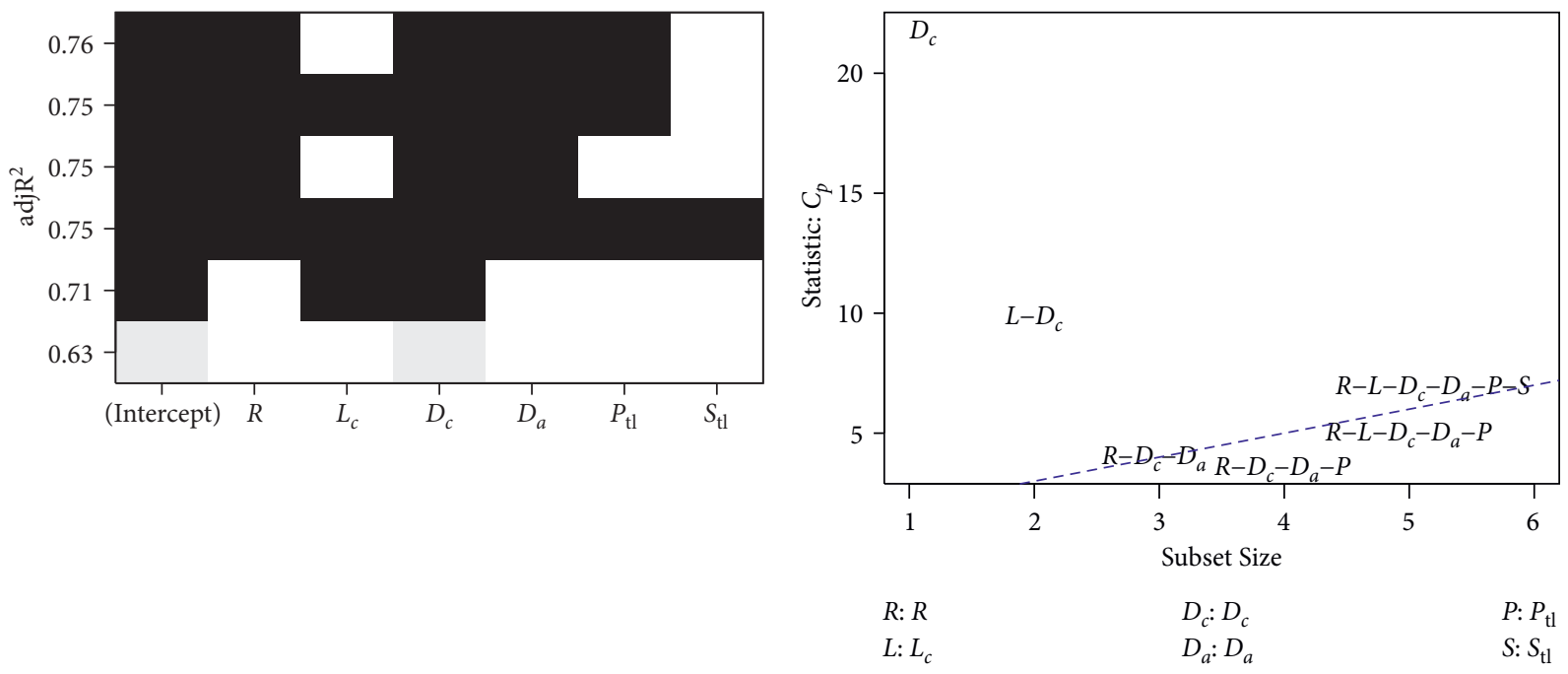

(a)

(b)

Figure 6: Model selection based on (a) adjusted $R$-square and (b) $C_{p}$ statistic.

used in the developed models vary in the studies mentioned earlier. In the present study, field experiments were performed on two-lane rural highways located in plain terrain. The models selected for comparison are chosen based on terrain type, the number of lanes, vehicle type, device used in data collection, and different explanatory variables (curve radius, curve length, deflection angle, degree of curve, and tangent length) considered. Hence, we selected similar studies for model comparison. Taylor's diagram was used to validate and compare the models. Taylor diagrams are mathematical diagrams represented graphically to determine how closely a pattern (or a set of patterns) resembles out-of-sample data [55]. The degree of correspondence between patterns to the out-of-sample data is quantified using three statistics: Pearson correlation coefficient, standard deviation, and centered root mean square difference. This allows one to gauge how precisely the model predictions match out-of-sample data. The pattern or set of patterns that lie close to the point marked on the $x$-axis "field data" (represents out-of-sample data) as shown in Figures 7(a) and 7(b), resembles a high degree of correspondence. Figures 7 (a) and 7 (b) are Taylor diagrams for deceleration and acceleration rate models, respectively, summarizing their degree of correspondence to the field data. Statistics of ten models for the deceleration rate and five models for the acceleration rate were calculated, and number was assigned to each corresponding symbol as shown in the diagrams.

Model 1 is the proposed deceleration rate model, as shown in Figure 7 (a) and Table 13. Its pattern correlation with the field data is between 0.90 and 0.95 . The green contours represent the centered root mean square (CRMS) difference, and its value for model 1 is close to $0.1 \mathrm{~m} / \mathrm{s}^{2}$. The radial distance from the origin represents the standard deviation (SD), and its value for model 1 is $0.23 \mathrm{~m} / \mathrm{s}^{2}$. This value is lesser than the SD of the field data $\left(\sim 0.24 \mathrm{~m} / \mathrm{s}^{2}\right)$. The models $(3,7,9$, and 10$)$ show strong pattern correlation with correlation coefficient values between 0.80 and 0.90 . The
CRMS values for these models are between 0.13 and $0.15 \mathrm{~m} /$ $\mathrm{s}^{2}$. The values of standard deviations for these models are below and close to the field data marked on the $x$-axis. The values of CRMS for models 2, 4, 5, and 8 are higher than $0.2 \mathrm{~m} / \mathrm{s}^{2}$ showing strong pattern correlation between 0.8 and 0.9 . Also, the values of the standard deviation are greater than the standard deviation of the field data. The values of MAD (mean absolute deviation) and RMSE (root mean square error) are computed for all the models and tabulated in Table 13. The proposed model 1 for the deceleration rate in this study showed a very strong correlation, low errors, and variations (CRMS, RMSE, MAD, and SD) in comparison to all the other models compared. Hence, model 1 proposed in this study predicts deceleration rate more accurately.

Furthermore, the Taylor diagram was used to validate and compare the acceleration rate models. A proposed model 11 from this study shows a strong pattern correlation with a correlation coefficient value between 0.70 and 0.80 . The value of CRMS is between 0.1 and $0.125 \mathrm{~m} / \mathrm{s}^{2}$. The SD value $(\sim 0.08)$ of the proposed model is below than that of the field data $(\sim 0.16)$. Models 12, 13, 14, and 15 show moderate correlation with correlation coefficient values between 0.50 and 0.70 . Also, the values of CRMS $\left(>0.125 \mathrm{~m} / \mathrm{s}^{2}\right)$ and SD $\left(>0.10 \mathrm{~m} / \mathrm{s}^{2}\right)$ are higher in comparison to model 11.The proposed model resulted in lower CRMS, SD, MAD, and RMSE, as shown in Figure 7(b) and Table 13. Hence, model 11 was chosen as the better predictor of acceleration rates.

Models ( 1 to $5,7,10,11,13,14$, and 15) based on field experiments (spot speed and instrumented vehicles) are located close to the field data. Also, their distance from the field data (marked on the $x$-axis in Figures $7(a)$ and $7(b)$ ) is lesser in comparison to models 2 and 12 from the driving simulator. Thus, the predictions from field study are more accurate in comparison to those obtained from the driving simulator. This inference is in line with the conclusion made by Malaghan et al. [6]. 


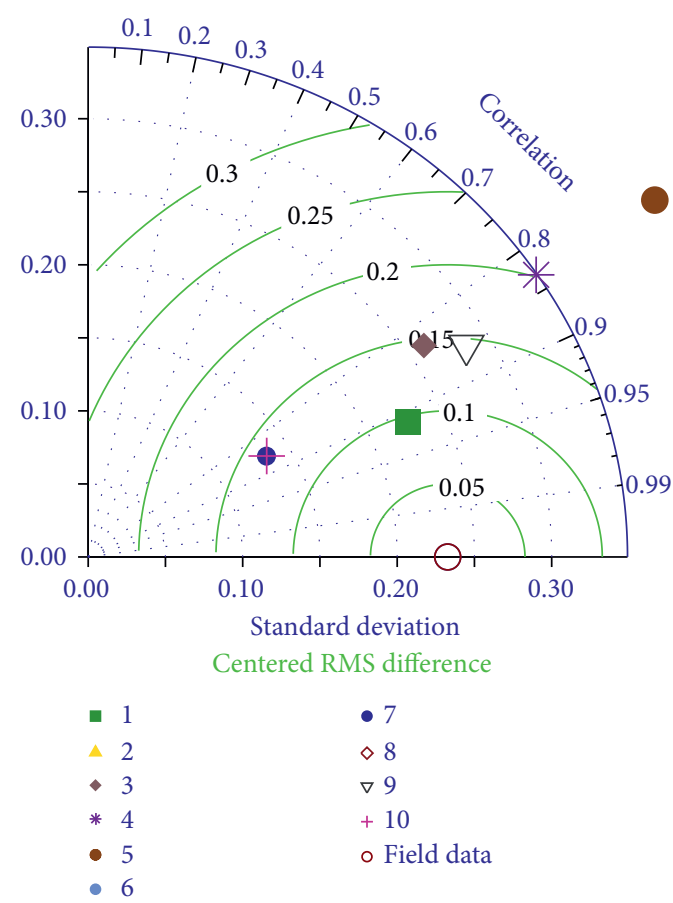

(a)

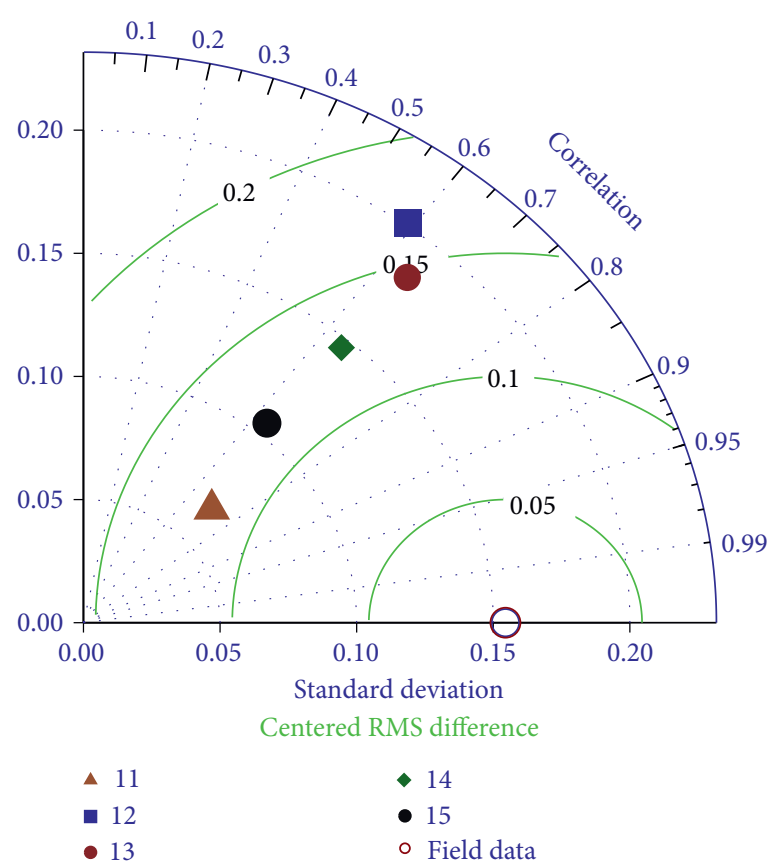

(b)

FIgURE 7: Taylor diagrams (a) deceleration rate models and (b) acceleration rate models.

TABle 13: Summary of the models and statistics.

\begin{tabular}{|c|c|c|c|c|}
\hline Model No. & Author & Models & MAD & RMSE \\
\hline \multicolumn{5}{|c|}{ Deceleration rate models } \\
\hline 1. & Proposed model & $d_{85}=0.522-3.985 * 10^{-04} R+0.046 D_{c}-0.004 D_{a}$ & 0.083 & 0.102 \\
\hline 2. & Bella [14] & $d_{85}=-1.316+148.28 / R+0.015 V_{85 t}$ & 0.281 & 0.405 \\
\hline 3. & Pérez-Zuriaga et al. [20] & $d_{85}=0.264+67.799 / R$ & 0.116 & 0.151 \\
\hline 4. & Pérez-Zuriaga et al. [21] & $d_{85}=0.447+90.472 / R$ & 0.392 & 0.441 \\
\hline 5. & Camacho-Torregrosa [5] & $d_{85}=0.313+114.436 / R$ & 0.435 & 0.517 \\
\hline 6. & Fitzpatrick et al. [27] & $d_{85}=0.6794-(295.14 / R)$ & 2.231 & 2.593 \\
\hline 7. & Crisman et al. [34] & $d_{85}=1.7568-0.2217 \operatorname{Ln}(R)$ & 0.126 & 0.162 \\
\hline 8. & Echaveguren and Basualto [35] & $d_{85}=131.41 / R$ & 0.295 & 0.419 \\
\hline 9. & Hashim et al. [37] & $d_{85}=-0.374+(12.52 / \sqrt{R})$ & 0.127 & 0.157 \\
\hline 10. & Marchionna and Perco [32] & $d_{85}=1.757-0.222 \ln (R)$ & 0.126 & 0.163 \\
\hline \multicolumn{5}{|c|}{ Acceleration rate models } \\
\hline 11. & Proposed model & $a_{85}=0.470-3.485 * 10^{-04} R+0.017 D_{c}-0.002 D_{a}$ & 0.092 & 0.130 \\
\hline 12. & Bella [14] & $a_{85}=-0.567+74.47 / R+0.007 V_{85 t}$ & 0.132 & 0.166 \\
\hline 13. & Camacho-Torregrosa [5] & $a_{85}=0.417+65.936 / R$ & 0.360 & 0.388 \\
\hline 14. & Echaveguren and Basualto [35] & $a_{85}=52.524 / R$ & 0.152 & 0.194 \\
\hline 15. & Hashim et al. [37] & $a_{85}=-0.211+(6.32 / \sqrt{R})$ & 0.205 & 0.316 \\
\hline
\end{tabular}

\section{Discussion}

Limited studies developed acceleration and deceleration rate models while approaching or departing horizontal curves. Most of these studies assumed constant operating speed between PC and PT and completion of deceleration/acceleration on the tangents. Moreover, most of these studies considered a single explanatory variable in the model formulation. In this regard, this research study proposed acceleration and deceleration rate models considering various geometric design features as the explanatory variables. Besides, the study did not make any assumption about speed variation and the occurrence of maximum/minimum speed values at specific locations on the successive road geometric elements.

A driving simulator study by Bella, supported the assumption of constant operating on the horizontal curve and speed value equal to that at MC [14]. The operating speed at MC was considered in the calculation of deceleration/acceleration rates. The results of our study indicate an ascending order of speed values at locations on the horizontal curves: $\mathrm{PC} / \mathrm{PT}>\mathrm{MC}>\mathrm{C}_{v \min }$ though a significant difference in mean speeds for a pair (MC and $C_{v \text { min }}$ ) was not found. In this study, the deceleration rates were calculated from the 
minimum speed values on the curve irrespective of its occurrence at a specific location (i.e., MC). The location of minimum speed (or end of deceleration) might not coincide with the MC all the time [56]. Thus, the prediction accuracy of our model is high in comparison to the model developed by Bella [14] based on the results shown in the previous section. Another possible reason could be experiments conducted in a virtual environment might not lead to accurate results as obtained from real-world experiments.

Most of the spot speed and instrumented vehicle studies considered a single explanatory variable, i.e., the radius of the curve to predict acceleration/deceleration rate. The exclusion/inclusion approach for the other geometric design variables in the model formulation was not detailed. In this study, various geometric variables leading to more accurate prediction of the acceleration/deceleration rate were accounted.

The $85^{\text {th }}$ percentile deceleration and acceleration rates ranged from $1.272 \mathrm{~m} / \mathrm{s}^{2}$ to $0.142 \mathrm{~m} / \mathrm{s}^{2}$ and $0.745 \mathrm{~m} / \mathrm{s}^{2}$ to $0.129 \mathrm{~m} / \mathrm{s}^{2}$, respectively. The values are different from a recommended value of $0.85 \mathrm{~m} / \mathrm{s}^{2}$ for both acceleration and deceleration rates. The study results are in line with the conclusions made by other studies [22, 27, 28].

\section{Conclusions}

This research study collected data using instrumented vehicles and primarily focused on developing models for deceleration and acceleration rate while approaching and departing the horizontal curve, respectively. Preliminary correlation analysis and all subset regression were used in developing acceleration/deceleration rate models. The study developed fourteen deceleration rate and sixteen acceleration rate models. AIC, Mallow $C_{p}$ statistic, and adjusted $R$ square were used in the selection of the best model among various developed models. The study also conducted a preliminary analysis to investigate the assumptions of constant speed between PC and PT for horizontal curves. The following conclusions were made from the analysis and results:

(1) The results of our study showed no significant difference between mean speeds measured at the end of deceleration and MC. However, considering the minimum speed at the end of deceleration instead at the MC in the calculation of deceleration/acceleration rate resulted in more accurate model predictions. The operating speeds at PC/PT are higher than the speeds at the end of deceleration and MC, indicating speed is not constant along the horizontal curve. This conclusion is in line with the previous studies' inference $[16,17,20]$.

(2) The $85^{\text {th }}$ percentile acceleration and deceleration rates were not equal and were found to be different from $0.85 \mathrm{~m} / \mathrm{s}^{2}$ as adopted in previous studies. The deceleration rates were found to be 1.43 times higher than the acceleration rates. This infers that the speed profile from tangent-to-curve and curve-to-tangent is not symmetric on either side of the end of deceleration (or minimum speed point) on the geometric element.

(3) The values of maximum operating speed even beyond 200 or $300 \mathrm{~m}$ from PC on the long tangents and minimum speed values at the end of deceleration were considered in the calculation of acceleration and deceleration rates. Also, the influence of design features of the horizontal curve such as curve radius, degree of curve, and deflection angle were included rather than a single variable, i.e., radius. This resulted in the improvement of acceleration and deceleration rate prediction accuracy which is evident from the Taylor diagram.

\section{Limitations and Future Scope}

This research study has a few limitations that provide scope for future research work:

(1) The presence of a GPS device might influence the normal driving behavior of drivers in short-term naturalistic driving studies. Although long-term naturalistic data collection is a challenging and exhaustive task; the developed models in this study can be checked or further improved in terms of their reliability and robustness.

(2) The results of this study indicated no significant difference in operating speeds measured at MC and end of deceleration in the horizontal curves. Further research should inspect whether a statistically significant difference exists in $85^{\text {th }}$ percentile speeds at $\mathrm{MC}$ and end of deceleration for more number of horizontal curves. Operating speed models at MC, $\mathrm{PC} / \mathrm{PT}$, and end of deceleration in the curve can be developed, and a comparison of the models can be made to check their robustness for speed prediction.

(3) The developed acceleration and deceleration rate models are 2D in nature, i.e., only horizontal alignment is considered. Future research should consider vertical alignment or a combination of both horizontal and vertical alignment.

(4) The static and dynamic characteristics coupled with driver behavior and road geometry might result in a significant difference in acceleration and deceleration rate for different vehicle classes. Furthermore, research can consider model development for heavy vehicles and combined models for both passenger cars and heavy vehicles.

(5) This study assumes a constant acceleration/deceleration rate between successive road geometric elements as calculated by the difference in operating speed between successive geometric elements to the distance between them. These models might not capture significant differences in deceleration and acceleration caused by the dynamic characteristics of vehicles. Future research can consider acceleration/ deceleration rates reflecting actual vehicle operating characteristics. 


\section{Data Availability}

The data used to support the findings of this study are available from the corresponding author upon request.

\section{Conflicts of Interest}

The authors declare that there are no conflicts of interest regarding the publication of this paper.

\section{References}

[1] A. Jacob and M. V. L. R. Anjaneyulu, "Operating speed of different classes of vehicles at horizontal curves on two-lane rural highways," Journal of Transportation Engineering, vol. 139, no. 3, pp. 287-294, 2013.

[2] D. Llopis-Castelló, F. J. Camacho-Torregrosa, and A. García, "Development of a global inertial consistency model to assess road safety on Spanish two-lane rural roads," Accident Analysis \& Prevention, vol. 119, pp. 138-148, 2018.

[3] I. Ahmed, "Road infrastructure and road safety," Transport and Communication Bulletin for Asia and Pacific, vol. 83, no. 1, pp. 19-25, 2013.

[4] MORTH (Ministry of Road Transport and Highways), Road Accidents in India 2019, MORTH, New Delhi, India, 2019.

[5] F. J. Camacho-Torregrosa, A. M. Pérez-Zuriaga, J. M. Campoy-Ungría, and A. García-García, "New geometric design consistency model based on operating speed profiles for road safety evaluation," Accident Analysis \& Prevention, vol. 61, pp. 33-42, 2013.

[6] V. Malaghan, D. S. Pawar, and H. Dia, "Modeling operating speed using continuous speed profiles on two-lane rural highways in India," Journal of Transportation Engineering, Part A: Systems, vol. 146, no. 11, Article ID 04020124, 2020.

[7] Y. Hassan, "Highway design consistency: refining the state of knowledge and practice," Transportation Research Record, vol. 1881, no. 1, pp. 63-71, 2004.

[8] V. Malaghan, D. S. Pawar, and H. Dia, "Speed prediction models for heavy passenger vehicles on rural highways based on an instrumented vehicle study," Transportation Letters, pp. 1-10, 2020 b.

[9] A. García, D. Llopis-Castelló, F. J. Camacho-Torregrosa, and A. M. Pérez-Zuriaga, "New consistency index based on inertial operating speed," Transportation Research Record: Journal of the Transportation Research Board, vol. 2391, no. 1, pp. 105-112, 2013.

[10] R. Lamm, E. M. Choueiri, and J. C. Hayward, "Tangent as an independent design element," Transportation Research Record, vol. 1195, pp. 123-131, 1988.

[11] R. A. Krammes, R. Q. Brackett, M. A. Shafer et al., Horizontal Alignment Design Consistency for Rural Two-Lane Highways, FHWA-RD-94-034, Federal Highway Administration, Mclean, VA, USA, 1995.

[12] J. L. Ottesen and R. A. Krammes, "Speed-profile model for a design-consistency evaluation procedure in the United States," Transportation Research Record: Journal of the Transportation Research Board, vol. 1701, no. 1, pp. 76-85, 2000.

[13] K. M. Collins and R. A. Krammes, "Preliminary validation of a speed-profile model for design consistency evaluation," Transportation Research Record: Journal of the Transportation Research Board, vol. 1523, no. 1, pp. 11-21, 1996.
[14] F. Bella, "Driver performance approaching and departing curves: driving simulator study," Traffic Injury Prevention, vol. 15, no. 3, pp. 310-318, 2014.

[15] F. Bella and A. Calvi, "Effects of simulated day and night driving on the speed differential in tangent-curve transition: a pilot study using driving simulator," Traffic Injury Prevention, vol. 14, no. 4, pp. 413-423, 2013.

[16] A. Montella, F. Galante, L. L. Imbriani, F. Mauriello, and M. Pernetti, "Simulator evaluation of drivers' behaviour on horizontal curves of two-lane rural highways," Advances in Transportation Studies: An International Journal, vol. 34, pp. 91-104, 2014a.

[17] A. Montella, L. Pariota, F. Galante, L. L. Imbriani, and F. Mauriello, "Prediction of drivers' speed behavior on rural motorways based on an instrumented vehicle study," Transportation Research Record: Journal of the Transportation Research Board, vol. 2434, no. 1, pp. 52-62, 2014 b.

[18] B. Dhahir and Y. Hassan, "Using horizontal curve speed reduction extracted from the naturalistic driving study to predict curve collision frequency," Accident Analysis \& Prevention, vol. 123, pp. 190-199, 2019.

[19] V. Malaghan, D. S. Pawar, and H. Dia, "Exploration of maximum and minimum operating speed positions on road geometric elements using continuous speed data," Journal of Transportation Engineering, Part A: Systems, 2021.

[20] A. M. P. Zuriaga, A. G. García, F. J. C. Torregrosa, and P. D'Attoma, "Modeling operating speed and deceleration on two-lane rural roads with global positioning system data," Transportation Research Record: Journal of the Transportation Research Board, vol. 2171, no. 1, pp. 11-20, 2010.

[21] A. M. Pérez-Zuriaga, F. J. Camacho-Torregrosa, and A. García, "Tangent-to-curve transition on two-lane rural roads based on continuous speed profiles," Journal of Transportation Engineering, vol. 139, no. 11, pp. 1048-1057, 2013.

[22] W. Hu and E. T. Donnell, "Models of acceleration and deceleration rates on a complex two-lane rural highway: results from a nighttime driving experiment," Transportation Research Part F: Traffic Psychology and Behaviour, vol. 13, no. 6, pp. 397-408, 2010.

[23] J. McFadden and L. Elefteriadou, "Evaluating horizontal alignment design consistency of two-lane rural highways: development of new procedure," Transportation Research Record: Journal of the Transportation Research Board, vol. 1737, no. 1, pp. 9-17, 2000.

[24] R. Lamm and B. L. Smith, "Curvilinear alinement: an important issue for more consistent and safer road characteristic," Transportation Research Record, vol. 1445, pp. 12-21, 1994.

[25] W. S. Homburger, L. E. Keefer, and W. R. Mcgrath, Transportation and Traffic Engineering Handbook, Prentice Hall, Hoboken, NJ, USA, 1982.

[26] R. Lamm, B. Psarianos, and T. Mailaender, Highway Design and Traffic Safety Engineering Handbook, McGraw-Hill, New York, NY, USA, 1999.

[27] K. Fitzpatrick, L. Elefteriadou, D. W. Harwood et al., Speed Prediction for Two-Lane Rural Highway, FHWA-RD-99-171, Federal Highway Administration, Washington, DC, USA, 2000.

[28] A. M. Figueroa Medina and A. P. Tarko, "Speed changes in the vicinity of horizontal curves on two-lane rural roads," Journal of Transportation Engineering, vol. 133, no. 4, pp. 215-222, 2007. 
[29] G. Sil, S. Nama, A. Maji, and A. K. Maurya, "Modeling 85th percentile speed using spatially evaluated free-flow vehicles for consistency-based geometric design," Journal of Transportation Engineering, Part A: Systems, vol. 146, no. 2, Article ID 04019060, 2020.

[30] T. Choudhari and A. Maji, "Effect of horizontal curve geometry on the maximum speed reduction: a driving simulator-based study," Transportation in Developing Economies, vol. 5, no. 2, pp. 1-8, 2019.

[31] A. Montella, F. Galante, F. Mauriello, and M. Aria, "Continuous speed profiles to investigate drivers' behavior on twolane rural highways," Transportation Research Record: Journal of the Transportation Research Board, vol. 2521, no. 1, pp. 3-11, 2015.

[32] A. Marchionna and P. Perco, "Operating speed-profile prediction model for two-lane rural roads in the Italian context," Advances in Transportation Studies, vol. 14, pp. 57-68, 2008.

[33] F. Bella, "Can driving simulators contribute to solving critical issues in geometric design?" Transportation Research Record: Journal of the Transportation Research Board, vol. 2138, no. 1, pp. 120-126, 2009.

[34] B. Crisman, P. Perco, A. Robba, and R. Roberti, "Deceleration model for two-lane rural roads," Advances in Transportation Studies, vol. 11, pp. 19-32, 2007.

[35] T. Echaveguren and M. Basualto, "Assessment of accelerations in the consistency of singleelements of horizontal alignment," in Proceedings of the XI Chilean Conference on Transportation Engineering, pp. 20-24, Chile, Santiago, October, 2003.

[36] D. Said, A. Halim, and Y. Hassan, "Methodology for driver behaviour data collection and analysis for integration in geometric design of highways," in Proceedings of the 4th International Symposium on Highway Geometric Design, Valencia, Spain, June 2009.

[37] I. H. Hashim, T. A. Abdel-Wahed, and Y. Moustafa, "Toward an operating speed profile model for rural two-lane roads in Egypt," Journal of Traffic and Transportation Engineering (English Edition), vol. 3, no. 1, pp. 82-88, 2016.

[38] J. Xu, W. Lin, X. Wang, and Y. M. Shao, "Acceleration and deceleration calibration of operating speed prediction models for two-lane mountain highways," Journal of Transportation Engineering, Part A: Systems, vol. 143, no. 7, Article ID 04017024, 2017.

[39] S. Nama, G. Sil, A. K. Maurya, and A. Maji, “Acceleration and deceleration behavior in departing and approaching sections of curve using naturalistic driving data," in Recent Advances in Traffic Engineering, pp. 693-704, Springer, Singapore, 2020.

[40] F. Bella, "Parameters for evaluation of speed differential," Transportation Research Record: Journal of the Transportation Research Board, vol. 2023, no. 1, pp. 37-43, 2007.

[41] F. Bella and G. D'Agostini, "Driving Simulation for Design Consistency," in Proceedings of the 4th TRB International Symposium on Highway Geometric Design, Valencia, Spain, June 2010.

[42] F. Bella, A. Calvi, and F. D’Amico, "Operating Speed prediction for italian two-lane rural roads using speed profiles from GPS data," in Proceedings of the 4th Road Safety and Simulation International Conference, Rome, Italy, October 2013.

[43] B. Wang, S. Hallmark, P. Savolainen, and J. Dong, "Examining vehicle operating speeds on rural two-lane curves using naturalistic driving data," Accident Analysis \& Prevention, vol. 118, pp. 236-243, 2018.
[44] B. Dhahir and Y. Hassan, "Studying driving behavior on horizontal curves using naturalistic driving study data," Transportation Research Record: Journal of the Transportation Research Board, vol. 2672, no. 17, pp. 83-95, 2018.

[45] K. A. Passetti and D. B. Fambro, "Operating speeds on curves with and without spiral transitions," Transportation Research Record: Journal of the Transportation Research Board, vol. 1658, no. 1, pp. 9-16, 1999.

[46] F. Russo, S. A. Biancardo, and M. Busiello, "Operating speed as a key factor in studying the driver behaviour in a rural context," Transport, vol. 31, no. 2, pp. 260-270, 2016.

[47] A. Maji, G. Sil, and A. Tyagi, "85th and 98th percentile speed prediction models of car, light, and heavy commercial vehicles for four-lane divided rural highways," Journal of Transportation Engineering, Part A: Systems, vol. 144, no. 5, Article ID 04018009, 2018.

[48] R. I. Kabacoff, $R$ in Action: Data Analysis and Graphics with $R$, Manning Publications, Shelter Island, NY, USA, 2nd edition, 2011.

[49] H. Akaike, "A new look at the statistical model identification," IEEE Transactions on Automatic Control, vol. 19, no. 6, pp. 716-723, 1974.

[50] C. L. Mallows, "Some comments on $C_{p}$ " Technometrics, vol. 15, no. 4, pp. 661-675, 1973.

[51] H.-Y. Kim, "Analysis of variance (ANOVA) comparing means of more than two groups," Restorative Dentistry \& Endodontics, vol. 39, no. 1, pp. 74-77, 2014.

[52] H. Abdi and L. J. Williams, "Tukey's honestly significant difference (HSD) test," Encyclopaedia of Research Design, vol. 3, pp. 583-585, 2010.

[53] P. Schober, C. Boer, and L. A. Schwarte, "Correlation coefficients," Anesthesia \& Analgesia, vol. 126, no. 5, pp. 1763-1768, 2018.

[54] T. C. Krehbiel, "Correlation coefficient rule of thumb," Decision Sciences Journal of Innovative Education, vol. 2, no. 1, pp. 97-100, 2004.

[55] K. E. Taylor, "Summarizing multiple aspects of model performance in a single diagram," Journal of Geophysical Research: Atmospheres, vol. 106, no. D7, pp. 7183-7192, 2005.

[56] D. Llopis-Castelló, B. González-Hernández, A. M. PérezZuriaga, and A. García, "Speed prediction models for trucks on horizontal curves of two-lane rural roads," Transportation Research Record: Journal of the Transportation Research Board, vol. 2672, no. 17, pp. 72-82, 2018. 